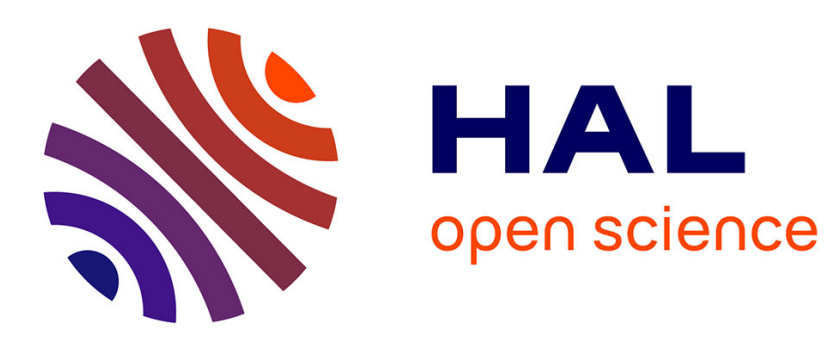

\title{
Breaking of the Bancroft rule for multiple emulsions stabilized by a single stimulable polymer
}

L. Besnard, M. Protat, F. Malloggi, J. Daillant, F. Cousin, N. Pantoustier, P. Guenoun, P. Perrin

\section{- To cite this version:}

L. Besnard, M. Protat, F. Malloggi, J. Daillant, F. Cousin, et al.. Breaking of the Bancroft rule for multiple emulsions stabilized by a single stimulable polymer. Soft Matter, 2014, 10, pp.7073-7087. 10.1039/c4sm00596a . hal-01157197

\author{
HAL Id: hal-01157197 \\ https://hal.science/hal-01157197
}

Submitted on 13 Nov 2015

HAL is a multi-disciplinary open access archive for the deposit and dissemination of scientific research documents, whether they are published or not. The documents may come from teaching and research institutions in France or abroad, or from public or private research centers.
L'archive ouverte pluridisciplinaire HAL, est destinée au dépôt et à la diffusion de documents scientifiques de niveau recherche, publiés ou non, émanant des établissements d'enseignement et de recherche français ou étrangers, des laboratoires publics ou privés. 


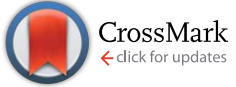

Cite this: Soft Matter, 2014, 10, 7073

\title{
Breaking of the Bancroft rule for multiple emulsions stabilized by a single stimulable polymer $\dagger$
}

\author{
L. Besnard, ${ }^{\text {abcd }}$ M. Protat, ${ }^{\text {abcd }}$ F. Malloggi, ${ }^{d}$ J. Daillant, ${ }^{\text {de }}$ F. Cousin, ${ }^{f}$ N. Pantoustier, ${ }^{\text {abc }}$ \\ P. Guenoun*d and P. Perrin*abc
}

We investigated emulsions of water and toluene stabilized by (co)polymers consisting of styrene (S) and 2-(dimethylamino)ethyl methacrylate (DMAEMA) monomer units with different compositions and structures such as a PDMAEMA homopolymer, a P(S-CO-DMAEMA) random copolymer and various PS$b$-PDMAEMA and PS-b-(S-CO-DMAEMA) block copolymers. The model system is used to study the fundamental conditions under which the different kinds of polymer-stabilized emulsions (direct oil in water, inverse water in oil and multiple emulsions) are stabilized or destabilized by $\mathrm{pH}$ change (at constant temperature). Polymer properties like chain conformation at the toluene-water interface as probed by SANS and neutron reflectivity at the liquid-liquid interface, the oil-water partitioning of the polymer chains (Bancroft's rule of thumb) as determined by UV spectroscopy and interfacial tensions measured by the rising and spinning drop techniques are determined. Overall, results evidence that the curvature sign, as defined by positive and negative values as the chain segments occupy preferentially the water and toluene sides of the interface respectively, reliably predicts the emulsion kind. In contrast, the Bancroft rule failed at foreseeing the emulsion type. In the region of near zero curvature the crossover from direct to inverse emulsions occurs through the formation of either unstable coexisting direct and inverse emulsions (i) or multiple emulsions (ii). The high compact adsorption of the chains at the interface as shown by low interfacial tension values does not allow to discriminate between both cases. However, the toluene-water partitioning of the polymeric emulsifier is still a key factor driving the formation of (i) or (ii) emulsions. Interestingly, the stabilization of the multiple emulsions can be tuned to a large extent as the toluene-water polymer partitioning can be adjusted using quite a large number of physico-chemical parameters linked to polymer architecture like diblock length ratio or polymer total molar mass, for example. Moreover, we show that monitoring the oil-water partitioning aspect of the emulsion system can also be used to lower the interfacial tension at low $\mathrm{pH}$ to values slightly higher than $0.01 \mathrm{mN} \mathrm{m}^{-1}$, irrespective of the curvature sign.

Received 18th March 2014

Accepted 28th May 2014

DOI: 10.1039/c4sm00596a

www.rsc.org/softmatter

\section{Introduction}

Emulsions are metastable dispersions of droplets of one liquid into another with typical sizes larger than 0.1 micrometer, the two liquids being essentially not miscible. The main two types of emulsions, so-called simple emulsions, are dispersions of either water droplets in oil (W/O, inverse) or oil droplets in water $(\mathrm{O} / \mathrm{W}$, direct). Multiple emulsions are more complex systems with either a water $(\ldots \mathrm{O} / \mathrm{W} / \mathrm{O} / \mathrm{W} \ldots / \mathrm{W})$ or an oil $(\ldots \mathrm{O} / \mathrm{W} / \mathrm{O} / \mathrm{W} \ldots)$ O) external continuous phase. Emulsions, mostly the simple $\mathrm{O} / \mathrm{W}$ and $\mathrm{W} / \mathrm{O}$ ones, are practically used in a wide variety of technological domains such as cosmetics, ${ }^{1}$ foods, ${ }^{2}$ pharmaceuticals and oil $^{3}$ industries to name a few. In many applications, not only the stability of the dispersions is important but also their triggered destabilization and inversion properties using various stimuli in accordance with applications. In particular, multiple emulsions are promising candidates to 
tackle the problem of delayed vitamin or enzyme delivery with adequate protection against oxidation ${ }^{4}$ and their potential can certainly be extended to other applications. ${ }^{5,6}$ However, very few commercial products exist because the preparation of stable multiple emulsions remains challenging ${ }^{7}$ and the promising applications foreseen in pharmaceuticals, ${ }^{\mathbf{8 , 9}} \operatorname{cosmetics}^{\mathbf{1 0 , 1 1}}$ or the food industry ${ }^{\mathbf{2 , 1 2}}$ have so far been impeded by the difficulty in making stable simple formulations.

Emulsifiers (i.e., surfactants, polymers and particles) are necessary to increase emulsion lifetime. It is widely accepted that the emulsion type depends chiefly on the emulsifier chemistry in a given physicochemical environment (ionic strength, temperature, pH...). Similarly, changing the emulsifier environment can act as a stimulus to trigger a change in the emulsion nature. ${ }^{13}$

In this communication we aim at discovering the key parameters that control the appearance of multiple emulsions in such sequences. Polymers are styrene (S) and poly(2-(dimethylamino)ethyl methacrylate) (DMAEMA) based block copolymers, whose conformation is highly sensitive to both $\mathrm{pH}$ and temperature. ${ }^{\mathbf{1 4 , 1 5}}$ These polymers were shown to stabilize different kinds of toluene-water emulsions and phase inversion is triggered by $\mathrm{pH}$ or temperature. ${ }^{\mathbf{1 6}}$ Moreover, the phase inversion reveals original features since the transition from direct to inverse emulsions can occur through the formation of stable multiple emulsions. Hence, in addition to the practical advantage that our multiple emulsions can be processed in a simple manner using a single emulsifier in one step, ${ }^{\mathbf{1 6}}$ our system is rather unique to investigate the fundamental conditions under which different kinds of emulsions are stabilized or destabilized.

Attempts to explain emulsion phase inversion are numerous especially in the case of surfactants. About a century ago, Bancroft in his "theory of emulsification" ${ }^{17}$ presented the famous empirical rule, which states that the continuous phase of the formed emulsion is the one that preferentially solubilizes surfactant molecules. This rule precisely states that the phase in which the surfactant molecules preferentially partition will be the continuous phase of the emulsion. To the best of our knowledge, it is remarkable to notice that the Bancroft rule never failed to predict the emulsion type for surfactants at concentrations higher than cmc (critical micelle concentration) ${ }^{18}$ Far from the inversion point, violation of the Bancroft rule was typically observed for the $\mathrm{C}_{12} \mathrm{E}_{5} / n$-heptane/NaCl $0.01 \mathrm{M}$ at low surfactant concentrations, typically below the surfactant's cmc. ${ }^{19}$ Under such conditions, emulsions are rather unstable. We reported on similar violation of the Bancroft rule for the $\mathrm{C}_{12} \mathrm{E}_{4} / n$-dodecane $/ \mathrm{NaNO}_{3} \quad 0.3 \mathrm{M} .^{20}$ Various approaches were then reported to give more quantitative criteria to predict the emulsion type. Hydrophile-Lipophile Balance (HLB) scales were developed by several authors within a framework that remains empirical since predictions take accounts of surfactant structures without consideration of environment effects. ${ }^{21,22}$ The HLD concept predicts the emulsion kind for surfactants by taking into account the environment effect but does not link the structural characteristics of the adsorbed chains at the interfaces to the emulsion kind. ${ }^{23}$
In the nineties, Kabalnov and Wennerström ${ }^{\mathbf{1 3}}(\mathrm{KW})$ proposed to revisit the disputable Harkins and Langmuir ${ }^{24,25}$ wedge theory, which links the sign of the droplet curvature to the surfactant mean spontaneous curvature $c_{0}$, for predicting the emulsion type. Indeed the two latter quantities are usually of very different orders of magnitude and cannot be readily compared. However, the KW thermodynamic approach, which compares the metastability of both $\mathrm{W} / \mathrm{O} / \mathrm{W}$ and $\mathrm{O} / \mathrm{W} / \mathrm{O}$ films formed in the case of coalescence events for inverse and direct emulsions respectively, gives a more satisfactory approach. Detailed calculations show that surfactant molecules with positive and negative mean spontaneous curvature, $c_{0}$, will preferentially form direct and inverse emulsions respectively, in agreement with Langmuir law. The KW theory appears reliable to predict the well-known "direct-unstable-inverse emulsion" transitional phase inversion sequence upon changing temperature, and hence $c_{0}$, for the $\mathrm{C}_{\mathrm{i}} \mathrm{E}_{\mathrm{j}}$-alkane-water systems. ${ }^{26,27}$ Provided that $c_{0}$ can be tuned upon changing chemistry and/or experimental parameters such as $\mathrm{pH}$ or ionic strength for instance, the $\mathrm{O} / \mathrm{W}$-unstable-W/O emulsion sequence can be observed in the presence of any surfactants, ionics and nonionics. ${ }^{18,28}$ As a matter of fact the mean curvature also controls the structures of microemulsions that, contrarily to emulsions, are at thermodynamic equilibrium..$^{13,29}$ Decreasing $c_{0}$ from positive to negative values allows the sweep of the Winsor I $\left(c_{0}>0\right)$-Winsor III $\left(c_{0} \approx 0\right)$-Winsor II $\left(c_{0}<0\right)$ sequence. Oil-swollen micelles form as $c_{0}$ is positive while water-swollen micelles form as $c_{0}$ is negative. Bi-continuous microemulsions are observed for $c_{0}$ close to zero. ${ }^{30,31}$ The nature of the equilibrium phase is thus precisely related to the mean spontaneous curvature of surfactants in a given environment. Since $c_{0}$ controls both equilibrium structures and emulsion types, several experimental studies have established a correlation between the Winsor sequence of phases at equilibrium and the out of equilibrium $\mathrm{O} / \mathrm{W}$-unstable-W/O emulsion sequence irrespective of surfactant types. ${ }^{13,28}$ The curvature approach thus provides tools that allow the prediction of the emulsion kind. With respect to multiple emulsions, they are usually prepared using a two-step process and two surfactants with opposite curvatures. $^{6,32}$ Consequently stable multiple emulsions cannot be prepared using a unique surfactant although it was theoretically suggested that the surfactant with $c_{0}$ around zero forming (multi)layers with high mean elastic modulus $(\kappa$ of order of 10-100 kT) could lead to stable multiple emulsions. ${ }^{13}$ However, even in the case of phospholipids for which high $\kappa$ are expected, ${ }^{33}$ it was shown that the transitional phase inversion does not pass through the formation of multiple emulsions. Instead, very unstable emulsions were obtained in the region of zero curvature. ${ }^{34}$

Polymers that adsorb at oil-water interfaces also stabilize emulsions. The repartition of the monomers at the interfaces between oil and water can be varied using $\mathrm{pH}, \mathrm{T}$... by modifying the repartition of segments that split between oil and water. One could then expect the emulsion type to be highly dependent on this conformation. A simple analogy with the surfactant case would be to define a curvature of the chain as related to the ratio of occupied volume on each side of the interface. Practically, the 
phase inversion sequence $\mathrm{O} / \mathrm{W}$-unstable-W/O was achieved using poly(acrylic acid) (PAA) chains modified with alkyl side chains using various parameters like number and length of the hydrophobic grafted moieties, $\mathrm{pH}$ or ionic strength. ${ }^{35,36}$ The phase inversion sequence was also successfully swept using light as a stimulus by combining $\mathrm{C}_{\mathrm{i}} \mathrm{E}_{\mathrm{j}}$ surfactants with photoresponsive polymers. ${ }^{37}$ In all cases, quantitative criteria to predict the emulsion type for polymeric emulsifiers are still lacking. On the qualitative side, we are aware of no exception to the Bancroft rule, which relies on the respective solubility of the macromolecules in oil and water and a single study reports on the possibility to achieve predictions using HLB scale for polymers. ${ }^{36}$

In this paper, we examine the correlation between polymer conformation and the emulsion type for a series of $\mathrm{S}$ and DMAEMA based polymers with various structures and compositions. As a stimulus, we used $\mathrm{pH}$ to monitor the emulsion kind, which was determined by confocal microscopy. The effect of the temperature stimulus on that system was reported elsewhere. ${ }^{16,38}$ To check the validity of the Bancroft rule, UV spectroscopy was performed to measure the oil-water phases partitioning of the polymeric emulsifier. The curvature is, as much as possible, deduced from conformation analysis by SANS, cryo-TEM and neutron reflectivity at the oil-water interface. The latter technique was developed specifically to investigate polymer conformation at a flat interface like that of an emulsion droplet. Interfacial tensions were measured as a function of $\mathrm{pH}$ to get insights into chain packing at interfaces. The main goal of our study is to probe in situ the conformation of adsorbed polymers to establish a quantitative relationship between the emulsion type (direct, inverse and multiple) and the chain curvature deduced from the conformation. We also demonstrate that stimulable stable multiple emulsions can be obtained using a single stimuli-responsive emulsifier and a simple one-step emulsification process. The latter feature was previously showed by Hong et al. for catastrophic phase inversion where double emulsions were prepared with a single polystyrene- $b$-poly(ethylene glycol) diblock copolymer ${ }^{39}$ as it is also the case for surfactants. ${ }^{40}$ The polymer leads to a stability improvement as compared to surfactants, for which the prepared emulsions are highly unstable. Hanson et al. obtained long-term stability double emulsions by using synthetic amphiphilic diblock copolypeptide emulsifiers. ${ }^{41}$ However, even if these systems offer easier formulation and stable multiple emulsions, they do offer neither an easy way of releasing potentially encapsulated active species nor a control over the emulsion morphologies. Simple methods to control the preparation of stimulable and stable multiple emulsions with polymers are thus lacking.

\section{Experimental}

\section{Polymers synthesis and characterizations}

The diblock copolymers used in this study consist of a block of polystyrene (PS) and a block of either 2-(dimethylamino)ethyl methacrylate (DMAEMA) unit or DMAEMA and styrene units. The $\mathrm{PS}_{x}-b$ - $\left(\mathrm{PS}_{y}-c o\right.$-PDMAEMA $\left.{ }_{z}\right)$ amphiphilic copolymers were synthesized by atom transfer radical polymerization (ATRP) via a "one-pot" process as detailed previously. ${ }^{16}$ The $\mathrm{PS}_{50}-b$ PDMAEMA $_{140}$ copolymer was synthesized by ATRP using the "halogen exchange" method as detailed in the ESI. $\dagger$ Size Exclusion Chromatography (SEC, Viscotek GPC max VE 2001; TDA 302 triple detector array) in THF containing 2\% triethylamine and ${ }^{1} \mathrm{H}$ NMR spectroscopy (Bruker $400 \mathrm{MHz}$ spectrometer) were used to determine molar masses, polydispersities (PDI) and precise compositions of each polymer. Each ( $\mathrm{PS}_{y}-\mathrm{Co}-$ PDMAEMA $_{z}$ ) hydrophilic block of the series of copolymers contains around $30 \% \mathrm{~mol}$ of styrene units distributed randomly. Table 1 summarizes the characteristics of the copolymers.

$N_{\mathrm{S}} / N_{\text {DMAEMA }}$ are the total number of styrene/DMAEMA units in the copolymer, $N_{1}$ is the number of monomer units (styrene) in the first block, $N_{2}$ is the number of monomer units in the second block and $N$ is the total number of monomer units.

\section{Samples preparation and characterizations}

Polymer water solubility measurements and titration. The water solubility of the polymers was investigated by adding polymers to water $\left(5 \mathrm{~g} \mathrm{~L}^{-1}\right)$ at a given $\mathrm{pH}$ at $25^{\circ} \mathrm{C}$. The aqueous polymer phases were then stirred using a magnetic bar for 24 hours before checking polymer solubility. Polymer titration was made following two different methods. In the first one, PDMAEMA $_{206}$ and $\mathrm{PS}_{56}$-Co-PDMAEMA ${ }_{138}$ aqueous solutions were prepared by dissolving the polymer in water at $\mathrm{pH} 1$ (protons are in large excess and chains are fully charged). The polymers were titrated by a $0.1 \mathrm{M}$ sodium hydroxide solution. The $\mathrm{p} K_{\mathrm{a}} \mathrm{s}$ were determined from the titration curves, which exhibit two well-separated $\mathrm{pH}$ jumps as aliquots of $0.1 \mathrm{M} \mathrm{NaOH}$ solution were added to the polymer solution. The first one

Table 1 Macromolecular characteristics of the copolymers

\begin{tabular}{|c|c|c|c|c|c|c|}
\hline Polymers $^{a}$ & $M_{\mathrm{n}}^{b}\left(\mathrm{~g} \mathrm{~mol}^{-1}\right)$ & $\mathrm{PDI}^{b}$ & $N_{\mathrm{s}}$ & $N_{1} / N$ & $N_{1} / N_{2}$ & $N_{\mathrm{s}} / N_{\text {DMAemA }}$ \\
\hline $\mathrm{PS}_{83}-b-\left(\mathrm{PS}_{54}-c o\right.$-PDMAEMA $\left.{ }_{128}\right)$ & 34300 & 1.2 & 0.52 & 0.31 & 0.46 & 1.07 \\
\hline $\mathrm{PS}_{48}-b-\left(\mathrm{PS}_{31}-c o-\mathrm{PDMAEMA}_{60}\right)$ & 17600 & 1.3 & 0.57 & 0.35 & 0.53 & 1.32 \\
\hline $\mathrm{PS}_{56}-$ co-PDMAEMA & 27500 & 1.3 & 0.29 & - & - & 0.41 \\
\hline $\mathrm{PS}_{50}-b$-PDMAEMA 140 & 27200 & 1.3 & 0.26 & 0.26 & 0.36 & 0.36 \\
\hline PDMAEMA $_{206}$ & 32400 & 1.2 & - & - & - & - \\
\hline
\end{tabular}

${ }^{a}$ Indexes being the average number of monomer units of each type. ${ }^{b}$ As determined by SEC analysis in THF containing $2 \%$ triethylamine. 
corresponds to the titration of $\mathrm{HCl}$ in excess and the second one to the titration of DMAEMA units.

The second method consists in the titration of the polymer chains transferred from toluene to the aqueous phase after having left the two phases in contact for 24 hours. The method is convenient to titrate the polymers, like $\mathrm{PS}_{48}-b-\left(\mathrm{PS}_{31}\right.$ - $c o$ PDMAEMA $_{60}$ ) and $\mathrm{PS}_{50}-b$-PDMAEMA 140 which cannot be solubilized directly into water. Attempts to solubilize the polymers in water indeed lead to polymer precipitation. The supernatant, separated from the polymer precipitate, does not contain measurable quantity of polymer as shown by dynamic light scattering and dry-extract content methods (not given here). Note that for similar block copolymers but soluble in water, extremely low values of the cmcs (of order of $10^{-8} \mathrm{M}$ ) were reported in the literature. ${ }^{42}$ Four polymers were actually titrated by the second method namely $\mathrm{PS}_{48}-b$-( $\mathrm{PS}_{31}-\mathrm{co}$-PDMAEMA $\left.{ }_{60}\right)$ and $\mathrm{PS}_{50}-b$-PDMAEMA ${ }_{140}$ and also PDMAEMA 206 and $\mathrm{PS}_{56}-\mathrm{co}$ PDMAEMA $_{138}$, which are water-soluble under acidic conditions. For the two latter polymers, the $\mathrm{p} K_{\mathrm{a}} \mathrm{s}$ measured by the two methods were similar within the measurements uncertainty. None of these two methods was adapted to the titration of $\mathrm{PS}_{83^{-}}$ $b$-( $\mathrm{PS}_{54}-\mathrm{co}$-PDMAEMA $\left.{ }_{128}\right)$ and $\mathrm{PS}_{65}-b$-( $\mathrm{PS}_{25}-\mathrm{co}$-PDMAEMA $\left.{ }_{55}\right)$ since they are not water soluble and do not transfer enough to water.

Aqueous and oil containing polymer phases in contact sample preparation. Each copolymer was first solubilized at $5 \mathrm{~g}$ $\mathrm{L}^{-1}$ in toluene. $\mathrm{HCl}$ and $\mathrm{NaOH}$ solutions (supplied by Merck) were used to prepare aqueous solutions at different pHs using MilliQ-water (Millipore, 18.2 M 2 ). Equal volume of toluene solution and the aqueous phase at given $\mathrm{pH}$ (initial $\mathrm{pH}$ ) were placed into contact at rest for 24 hours at $25{ }^{\circ} \mathrm{C}$ in glass tubes and $\mathrm{pH}$ of the aqueous phase was measured again. Thus, the $\mathrm{pH}$ values reported here actually correspond to those obtained after a contact of 24 hours between all species. Potentiometry (see second method), UV spectroscopy, tensiometry, SANS, neutron reflectivity and cryo-TEM experiments were carried out prior to emulsification. The emulsion type and stability were then investigated, all experiments being performed at $25{ }^{\circ} \mathrm{C}$. The use of temperature as a stimulus was detailed elsewhere. ${ }^{16,38}$

UV spectroscopy. The partitioning of the polymers between the oil and water phases was followed by UV spectroscopy measurements as a function of time at various pHs. In particular, the amount of copolymer chains that transfers from toluene to the aqueous phases after a contact of 24 hours was determined as it gives information on chain distribution prior to emulsification. Absorbance measurements were carried out with a UV-vis Hewlett-Packard 8453 spectrophotometer using a quartz cell of $10 \mathrm{~mm}$ path, in a wavelength range from 200 to $1100 \mathrm{~nm}$. The chain transfer was monitored by measuring the absorbance at $254 \mathrm{~nm}$ of the benzene ring of styrene units. $\mathrm{PS}_{x^{-}}$ $b$-( $\mathrm{PS}_{y}$-co-PDMAEMA $)$ polymer concentration in water (expressed in $\mathrm{g} \mathrm{L}^{-1}$ ) was determined using the water-soluble $\mathrm{PS}_{56}$ - $\mathrm{Co}$-PDMAEMA ${ }_{138}$ calibration curve in pure water at $25{ }^{\circ} \mathrm{C}$ (ESI, Fig. $1 \dagger$ ). The calibration curves at pH 1, pH 3 and pH 5 were all identical leading to the following equation:

$$
\text { copolymer concentration }=\frac{|(254 \mathrm{~nm})| \bar{M}(x+y+z)}{\varepsilon_{254 \mathrm{~nm}}(x+y)}
$$

with $\varepsilon_{254 \mathrm{~nm}}=262 \mathrm{~L} \mathrm{~mol}^{-1} \mathrm{~cm}^{-1}$ and $\bar{M}$ the mean molar mass per unit. The water polymer concentration dependence with time was determined after subtraction of the toluene absorbance used as a blank since toluene is slightly soluble in water. Using a cell with equal volume of water and toluene, a blank was then run to measure the transfer kinetics of toluene molecules to water. The knowledge of the polymer concentration in water allows quantifying chain partitioning from toluene to water as a function of time and in particular after 24 hours (ESI Fig. $2 \dagger$ ). We report on the ratio (\%) of the polymer mass concentrations in water $\left(\mathrm{g} \mathrm{L}^{-1}\right)$ after partitioning to the initial polymer mass concentration in toluene before transfer $\left(5 \mathrm{~g} \mathrm{~L}^{-1}\right)$.

Cryo-transmission electron microscopy (cryo-TEM). The morphology and size of structures formed by copolymers in aqueous phases after partitioning were determined from cryoTEM images. A drop of aqueous phase was deposited on a carbon membrane. The excess of liquid on the membrane was blotted out with a filter paper and the membrane was quenchfrozen in liquid ethane to form a thin vitreous ice film. Observations were conducted on a JEOL microscope at low temperature $\left(-180{ }^{\circ} \mathrm{C}\right)$. The contrast arises from the differences in the electron densities of the sample molecules. The electron density, $\rho$, is given by the equation:

$$
\rho=\frac{\mu N_{\mathrm{A}}}{M} \sum_{i} Z_{i} n_{i}
$$

with $Z_{i}$, the atomic number of the $i$ atom, $n_{i}$, the number of $i$ atoms in the molecules, $\mu$, the density, $M$, the molar mass and $N_{\mathrm{A}}$, the Avogadro number. The electron densities of the elements composing the copolymer aqueous solutions are given in Table 2.

According to the $\rho$ values, the DMAEMA $\mathrm{Cl}$ and the $\mathrm{S}_{0.3}-\mathrm{co}$ DMAEMA $_{0.7} \mathrm{Cl}$ are the most visible entities using cryo-TEM. However, with the reasonable assumption that block copolymer chains self-assemble by forming hydrophobic core-hydrophilic shell aggregates, we come to the conclusion that the hydrophilic parts of the block copolymers are not concentrated enough (i.e.; the average electronic density of the shell is too close to that of water) to be seen by cryo-TEM. However, the hydrophobic PS blocks are sufficiently contrasted to provide structural information on the aggregate hydrophobic cores.

Tensiometry. Interfacial tension was measured using a drop shape analyzer (Tracker device from Teclis). The toluene phase

Table 2 Electron densities of the elements composing the copolymer

\begin{tabular}{|c|c|c|c|c|}
\hline Elements & $\sum_{i} z_{i} n_{i}$ & $\mu\left(\mathrm{g} \mathrm{cm}^{-3}\right)$ & $M\left(\mathrm{~g} \mathrm{~mol}^{-1}\right)$ & $\rho\left(\mathrm{e}^{-} \AA^{3}\right)$ \\
\hline $\mathrm{H}_{2} \mathrm{O}$ & 10 & 1 & 18 & 0.33 \\
\hline Styrene & 56 & 1.06 & 104.2 & 0.34 \\
\hline $\mathrm{S}_{0.3}-c o-\mathrm{DMAEMA}_{0.7} \mathrm{Cl}$ & 94 & 1.24 & 167.3 & 0.42 \\
\hline DMAEMA Cl & 103 & 1.32 & 157 & 0.52 \\
\hline Toluene & 50 & 0.867 & 92.1 & 0.28 \\
\hline
\end{tabular}
aqueous solutions 
was loaded into a syringe and injected through a U-shaped needle into an optical glass cuvette containing the aqueous phase at final $\mathrm{pH}$. The droplet formed at the tip of the needle is illuminated to capture and analyze the droplet profile using a CCD camera. The drop profile can be solved from the LaplaceYoung equation and hydrostatic calculations to determine interfacial tensions.

The spinning drop tensiometer (SVT 20N, Dataphysics) was used to measure interfacial tension typically lower than $\gamma<1$ $\mathrm{mN} \mathrm{m} \mathrm{m}^{-1}$. The set-up consists of a horizontal glass capillary rotating about its long axis with a maximum speed of 10000 $\mathrm{rpm}$. The capillary was carefully filled with the aqueous phase at working $\mathrm{pH}$, avoiding formation of air bubbles. Copolymer in toluene solution was then injected with a microliter syringe. The elongation of the toluene droplet stops when the centrifugal forces are balanced by the interfacial tension forces. By measuring the cylinder radius, the interfacial tension was determined from the Vonnegut's equation. ${ }^{43}$

For both techniques, the interfacial tensions were measured after having left the oil and water phases in contact for 24 hours. After formation of the drop, spinning and/or rising, the interfacial tension was followed as a function of time for several hours. As shown in the ESI $\uparrow$ for $\mathrm{PS}_{48}-b-\left(\mathrm{PS}_{31}-c o\right.$-PDMAEMA 60$)$ at different $\mathrm{pHs}$, the characteristic time of the exponential relaxation is less than one hour, as it was the case for all the investigated polymers.

Small angle neutron scattering (SANS). SANS experiments were performed at the Léon Brillouin Laboratory (LLB in Saclay) on the PAXY spectrometer. Three spectrometer configurations have been used in order to cover a $q$ range from $4 \times 10^{-3}$ to $0.42 \AA^{-1}$. The aqueous phase was a mixture of $\mathrm{D}_{2} \mathrm{O}: \mathrm{H}_{2} \mathrm{O} 90: 10$ of scattering length density equal to that of deuterated toluene. Two contrasts were used: (i) in order to observe chains only, copolymers were solubilized in deuterated toluene at $5 \mathrm{~g} \mathrm{~L}^{-1}$ (this contrast is called "film") and (ii) to observe chains and oil, copolymers were solubilized in hydrogenated toluene at $5 \mathrm{~g} \mathrm{~L}^{-1}$ and this contrast is called "bulk". The investigated aqueous phases were introduced in a rectangular quartz cell with thickness $2 \mathrm{~mm}$. The blank sample was a $\mathrm{D}_{2} \mathrm{O}: \mathrm{H}_{2} \mathrm{O} 90: 10$ mixture that was left at rest in contact with toluene. Data treatment was done with the PasiNET software (LLB). Absolute values of the scattering intensity $\left(I(q)\right.$ in $\left.\mathrm{cm}^{-1}\right)$ were obtained from the direct determination of the number of neutrons in the incident beam and the detector cell solid angle. ${ }^{44}$ The signal of the $\mathrm{D}_{2} \mathrm{O}: \mathrm{H}_{2} \mathrm{O} 90$ : 10 blank sample was first subtracted.

Neutron reflectivity. A dedicated cell was built for measuring the reflectivity at the water-toluene interface. Our cell is composed of a lower hydrophilic sapphire wafer and an upper hydrophobic glass separated by a PDMS spacer of about 5 millimeters, all enclosed in a aluminum structure as shown in the ESI. $\dagger$ The principle is to spread a partially deuterated water sub-phase (same contrasts as sapphire) on the sapphire (total wetting) and to spread the toluene solution on top of the water. The neutron beam enters from below through a sapphire window and is reflected at the toluene-water interface. The water phase is then sucked out and the reflected signal (white beam) is collected at different thicknesses of water. When the thickness reaches about a hundred microns a well-defined reflected beam is observed in reflectivity position. Data were accumulated in a time of flight configuration at this position for two angles as well as for the direct beam at the same angles. The shape and intensity of the beam were also measured for different water thicknesses in order to correct for water scattering along the beam path and normalize the signal to a true reflectivity of the interface. It is worth noting that only few previous studies were reported about liquid-liquid neutron reflectivity. The pioneering studies due to Lee et $a .^{45}$ and Cosgrove et al. $^{\mathbf{4 6}}$ regarded alkane-water interfaces with a neutron beam travelling through a very thin alkane layer. Another class of study was designed by Zarbakhsh et al. ${ }^{47}$ by means of a frozen alkane substrate on top of which a water layer was spread and maintained after thawing the oil phase.

Preparation of the emulsions. Emulsions stabilized by the copolymers were obtained by homogenizing the toluene and aqueous phases left in contact for 24 hours using an Ultra Turrax T10 homogenizer ( $8 \mathrm{~mm}$ head) operating at $25000 \mathrm{rpm}$ for $40 \mathrm{~s}$. The emulsion type was directly observed by Laser Confocal Scanning Microscopy (CLSM) using Nile Red in toluene as a hydrophobic fluorophore. Confocal imaging was done in a quartz cell ( $0.5 \mathrm{~mm}$ light path) through an Olympus Fluoview FV1000 inverted confocal microscope. $150 \mu \mathrm{L}$ tagged emulsion samples were placed in the cell at room temperature, $25{ }^{\circ} \mathrm{C}$. IMARIS ${ }^{\circ}$ software (Bitplane) was used to create $3 \mathrm{D}$ reconstruction images.

\section{Results}

\section{General properties of the polymers}

In this study, we essentially used diblock copolymers made up of a block of polystyrene (PS) and a block consisting of either pure 2-(dimethylamino)ethyl methacrylate (DMAEMA) monomer units or randomly distributed units of styrene and of DMAEMA. To some extent, we also investigated some properties of a PDMAEMA homopolymer (PDMAEMA $\left.{ }_{206}\right)$ and of a random copolymer of styrene and DMAEMA units $\left(\mathrm{PS}_{56}-\mathrm{co}\right.$ PDMAEMA $_{138}$ ) (Table 1). Acido-basic titrations were carried out to determine the $\mathrm{p} K_{\mathrm{a}}$ of the polymers (Table 3 ) and investigate their solubility $\left(5 \mathrm{~g} \mathrm{~L}^{-1}\right)$ with $\mathrm{pH}$ (data not shown here).

PDMAEMA is a weak polybase, whose water solubility depends strongly on $\mathrm{pH}$. However, at $25{ }^{\circ} \mathrm{C}$, the homopolymer is soluble in water irrespective of $\mathrm{pH}$. Due to the presence of $\mathrm{S}$ units, the $\mathrm{p} K_{\mathrm{a}}$ of the $\mathrm{PS}_{56}-\mathrm{co}$-PDMAEMA ${ }_{138}$ chains is 6.8 and the solubility limit is shifted to lower $\mathrm{pH}$. The random copolymer chains precipitate as $\mathrm{pH}$ is increased above 6.2. Under same

Table $3 \mathrm{p} K_{\mathrm{a}}$ values of the polymers obtained by acid-basic titrations at $25{ }^{\circ} \mathrm{C}$

\begin{tabular}{ll}
\hline Polymers & $\mathrm{p} K_{\mathrm{a}}$ \\
\hline PDMAEMA $_{206}$ & 7 \\
PS $_{56}-c o-\mathrm{PDMAEMA}_{138}$ & 6.8 \\
$\mathrm{PS}_{50}-b$-PDMAEMA & \\
$\mathrm{PS}_{48}-b-\left(\mathrm{PS}_{31}-c o-\mathrm{PDMAEMA}_{60}\right)$ & 6.7 \\
\end{tabular}


conditions, $\mathrm{PS}_{50}-b$-PDMAEMA ${ }_{140}\left(\mathrm{p} K_{\mathrm{a}}\right.$ of 6.7$)$ does not dissolve in water at any $\mathrm{pH}$. The $\mathrm{p}_{\mathrm{a}}$ of $\mathrm{PS}_{48}-b$-( $\mathrm{PS}_{31}-c o$-PDMAEMA 60$)$ is 6.5. Regarding solubility, the three PS- $b$-(PS-co-PDMAEMA) polymers are not soluble within the range of $\mathrm{pH}$.

\section{Probing toluene-water partitioning of the polymers using UV- spectroscopy}

To probe the validity of the Bancroft rule, we investigated the distribution of polymer chains within the oil and aqueous phases as a function of $\mathrm{pH}$ using UV absorption spectroscopy. For instance, Fig. 1 presents the chain transfer kinetics of the $\mathrm{PS}_{56}$-co-PDMAEMA ${ }_{138}$ copolymer at $\mathrm{pH}$ 1.2.

The spectra show that the absorbance remains constant after 7 hours, which means that equilibrium conditions are indeed reached after 24 hours. The same remarks hold for all the studied polymers, therefore meaning that sample emulsification is made once chain transfer is completed. Fig. 2 displays the overall distribution of the copolymers after a contact of 24 hours between the oil and water phases as a function of $\mathrm{pH}$.

The presence of styrene in the copolymer chain obviously influences chain transfer. For instance, at $\mathrm{pH} 1.1,64 \%$ of the $\mathrm{PS}_{56}$ - o-PDMAEMA 138 chains transfer from toluene to water. Adding to the chain a relatively long PS block, as it is the case for the $\mathrm{PS}_{83}-b$ - $\left(\mathrm{PS}_{54}-c o\right.$-PDMAEMA $\left.{ }_{128}\right)$, decreases the water transfer to almost zero (about 1\%). Decreasing total molecular weight but keeping constant both the overall S/DMAEMA composition and the block length ratio $\left[\mathrm{PS}_{83}-b-\left(\mathrm{PS}_{54}-\mathrm{co}\right.\right.$-PDMAEMA $\left.{ }_{128}\right) \rightarrow$ $\mathrm{PS}_{48}-b$ - $\left(\mathrm{PS}_{31}\right.$-co-PDMAEMA 60$\left.)\right]$ considerably increases chain transfer up to $39 \%$. Increasing both the S/DMAEMA ratio and the PS block length while keeping constant the total molar mass, $\left[\mathrm{PS}_{48}-b-\left(\mathrm{PS}_{31}\right.\right.$ - $c o$-PDMAEMA 60$) \rightarrow \mathrm{PS}_{65}-b-\left(\mathrm{PS}_{25}-c o\right.$ PDMAEMA $\left._{55}\right)$ ], decreases chain transfer to about $1.5 \%$. Finally, random distribution of $S$ and DMAEMA units increases chain transfer from toluene to water as compared to diblock distribution of $\mathrm{S}$ and DMAEMA units [60\% for $\mathrm{PS}_{50}-b$-PDMAEMA 140 $\rightarrow 64 \%$ for $\mathrm{PS}_{56}$-Co-PDMAEMA $\left.{ }_{138}\right]$. On the pH side, Fig. 2 shows that the water affinity of the chains decreases strongly when $\mathrm{pH}$ increases as the chain ionization decreases rapidly at $\mathrm{pH}$ above $\mathrm{p} K_{\mathrm{a}}$. Hence, as expected, the structure of this series of copolymers offers various possibilities ( $\mathrm{pH}, \mathrm{S} / \mathrm{DMAEMA}$ composition

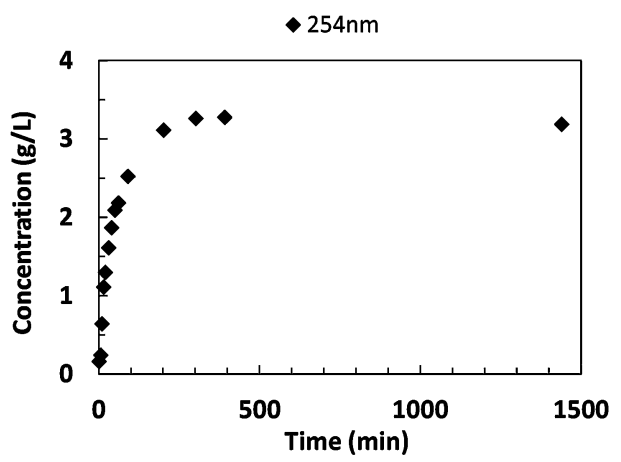

Fig. 1 Concentration of the PS ${ }_{56}$-CO-PDMAEMA $A_{138}$ copolymer in the aqueous phase as a function of the contact time between the two phases (pH 1.2).

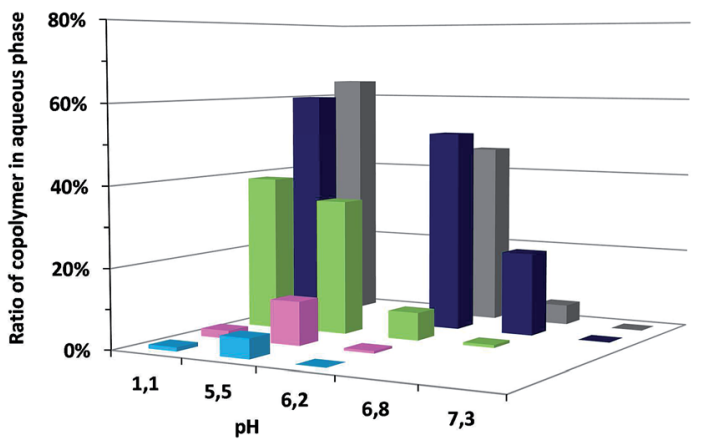

Fig. 2 Histogram summarizing copolymer's concentrations in aqueous phases after having left the toluene and water phases in contact for $24 \mathrm{~h}$ at $25^{\circ} \mathrm{C}$. pH values were measured after $24 \mathrm{~h}$. From front to back: I: $\mathrm{PS}_{83}-b-\left(\mathrm{PS}_{54}-\mathrm{CO}-\mathrm{PDMAEMA_{128 } )}\right.$; : $: \mathrm{PS}_{65}-b-\left(\mathrm{PS}_{25}-\right.$ CO-PDMAEMA $\left.A_{55}\right)$;: $\quad \mathrm{PS}_{48}-b-\left(\mathrm{PS}_{31}-\mathrm{CO}-\mathrm{PDMAEMA} \mathrm{A}_{60}\right) ; \quad$ i: $\mathrm{PS}_{50}-b-$ PDMAEMA $_{140}$; : $:$ PS $_{56}-$ CO-PDMAEMA 138 .

and distribution, block length ratio, total molar mass) to adjust the distribution of the chains between the two phases.

\section{Investigating self-assemblies of copolymer chains by cryo- TEM}

As reviewed in the introduction part, the emulsion type can be closely linked to the nature of the microemulsions and hence, to the structure of possible aggregates formed in water. We then investigated how copolymer chains were transferred in water after 24 hours of contact between the oil and water phases. The oil/water/copolymer system is likely to reach thermodynamic equilibrium as UV measurements showed that the chain partitioning across the interface was completed (Fig. 1). Among the investigated block copolymers, only the $\mathrm{PS}_{50}-b$-PDMAEMA 140 and $\mathrm{PS}_{48}-b$-( $\mathrm{PS}_{31}-c o$-PDMAEMA $\left.{ }_{60}\right)$ copolymers transfer enough chains in water to form aggregates detectable by cryo-TEM. The self-assembly in water of both copolymers at $\mathrm{pH}$ below $\mathrm{p} K_{\mathrm{a}}$ is presented in Fig. 3.

The aggregates are spherical and relatively uniform in size. Image analysis was performed to determine their size by counting about one hundred objects. At pH 1.2, hydrophobic core mean radii, $R_{\mathrm{C}}$, of $7.8 \pm 1.6 \mathrm{~nm}$ and $6.5 \pm 1.5 \mathrm{~nm}$ were measured for the $\mathrm{PS}_{50}-b$-PDMAEMA 140 and $\mathrm{PS}_{48}-b-\left(\mathrm{PS}_{31}-c o\right.$ PDMAEMA $_{60}$ ) copolymers respectively. The size decreases with $\mathrm{pH}$ with a radius of $5.1 \pm 0.8 \mathrm{~nm}$ at $\mathrm{pH} 6.2$ for $\mathrm{PS}_{50}-b$ PDMAEMA $_{140}$ and $3.7 \pm 0.5 \mathrm{~nm}$ at $\mathrm{pH} 5.5$ for $\mathrm{PS}_{48}-b-\left(\mathrm{PS}_{31}-c o-\right.$ PDMAEMA $_{60}$ ). Fig. 3 also shows that there are more aggregates at $\mathrm{pH} 1.2$ than at $\mathrm{pH} 5$ and 6.2. These aggregates seem to selforganize in a crystalline array but as discussed in the ESI, $\dagger$ the ordered structure likely arises from the cryo-TEM sample preparation and does not faithfully give a true picture of the more dilute bulk micelle solution. The cryo-TEM technique is, however, reliable with respect to the form and size of the aggregates. First, core sizes that are between $3.7 \mathrm{~nm}$ and $7.8 \mathrm{~nm}$ do not exceed the size of the fully stretched PS chain, $L=12 \mathrm{~nm}$ for $\mathrm{PS}_{48}-b$-( $\left.\mathrm{PS}_{31}-c o-\mathrm{PDMAEMA}_{60}\right)$ and $12.5 \mathrm{~nm}$ for $\mathrm{PS}_{50}-b$ PDMAEMA $_{140}$, as expected. Second, the object size should be discussed with respect to the presence or absence of toluene 

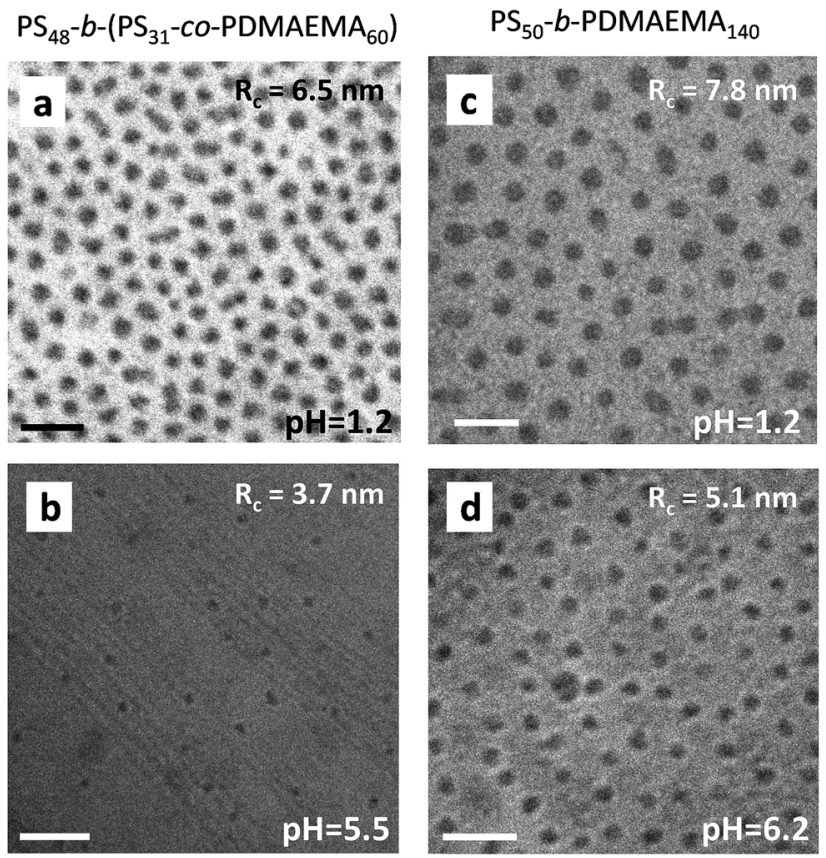

Fig. 3 Cryo-TEM pictures obtained from the $\mathrm{PS}_{48}-b-\left(\mathrm{PS}_{31}-\mathrm{CO}-\right.$ PDMAEMA ${ }_{60}$ ) copolymer in water at $\mathrm{pH}=1.2$ (a) and $\mathrm{pH}=5.5$ (b) and from $\mathrm{PS}_{50}-b$-PDMAEMA 140 copolymer in water at $\mathrm{pH}=1.2$ (c) and $\mathrm{pH}$ $=6.2$ (d). Scale bar represents $50 \mathrm{~nm}$. The mean radius of spheres is given in insert for each picture.

within the core. Assuming a toluene free micelle core (i.e. a homogeneous PS bead), the aggregate number, $p$, of the spherical micelles can be written as:

$$
p=\frac{4 \pi \rho_{\mathrm{C}} N_{\mathrm{A}} R_{\mathrm{C}}{ }^{3}}{M_{\mathrm{W}}^{\mathrm{PS}}}
$$

with $\rho_{\mathrm{C}}=1.04 \mathrm{~g} \mathrm{~cm}^{-3}$, the PS density, and $M_{\mathrm{W}}^{\mathrm{PS}}$, the PS block weight average molar mass. For the $\mathrm{PS}_{48}-b-\left(\mathrm{PS}_{31}-\mathrm{co}-\right.$ PDMAEMA $_{60}$ ) copolymer, $p$ is equal to 137 at $\mathrm{pH}$ 1.2. This value can be compared to the value of $p=70$ obtained for frozen spherical micelles formed in water at $\mathrm{pH} 1.2$ (and hence, completely free of oil) using $\mathrm{PS}_{42}-b$ - $\left(\mathrm{PS}_{29}\right.$-co-PDMAEMA 67$)$ chains, a copolymer very similar in size and composition. ${ }^{48}$ With such aggregate numbers in a ratio of 2 , toluene molecules probably swell the hydrophobic core in a way similar to the behavior of surfactant molecules under Winsor I conditions.

\section{Small angle neutron scattering}

At $\mathrm{pH}$ 1.2, SANS spectra for the two contrasts of $\mathrm{PS}_{48}-b-\left(\mathrm{PS}_{31}-c 0-\right.$ PDMAEMA $_{60}$ ) are shown in the ESI. $\dagger$ The difference in scattered intensity between both contrasts proves that toluene is indeed included in the hydrophobic moieties. For $\mathrm{PS}_{50}-b$-PDMAEMA ${ }_{140}$ in bulk contrast, a clear asymptotic $q^{-1}$ behavior is observed. This signal is reminiscent of rod-like objects scattering and suggests a model where the corona is a charged brush made of stretched polyelectrolyte chains assembled around a spherical core as suggested by cryo-TEM pictures. The model neglects interactions between the swollen micelles and considers each object to be made of a spherical homogeneous core of scattering amplitude $A_{\mathrm{c}}$ surrounded by a spherical heterogeneous shell representing the charged brush of average scattering amplitude $\left\langle A_{\mathrm{s}}\right\rangle^{.49}$ This amounts to writing the scattering intensity as:

$$
I=\left\langle\left(A_{\mathrm{c}}+A_{\mathrm{s}}\right)^{2}\right\rangle=\left(A_{\mathrm{c}}+\left\langle A_{\mathrm{s}}\right\rangle\right)^{2}+\left\langle\delta A_{\mathrm{s}}\right\rangle^{2}
$$

We then make the approximation that $\left\langle\delta A_{\mathrm{s}}\right\rangle^{2}$ is equal to the sum of $p$ associated independent rod-like chains (which ensures a correct $q^{-1}$ asymptotic dependence at high $q$ ) and we assume that $\left\langle A_{\mathrm{s}}\right\rangle$ is well represented by a power-law monomer profile in agreement with the rod-like statistics. Details of the mathematical formulation can be found in ref. 49 and 50 . The final fit function depends on four parameters which are the micelle concentration, the core radius $r_{\mathrm{c}}$ (whose value must be in agreement with cryo-TEM determination), the number of chains per micelle, $p$, and the brush extension $L$. The latter value must be close to the extension of a fully charged spherical brush, known from previous measurements. The best fit of the data for the bulk contrast is shown in Fig. 4 and gives $p=130$ with $L=165 \AA$ and $r_{\mathrm{c}}=93 \AA$. The latter core radius value is in agreement with cryo-TEM determination and $L$ must be compared to $\alpha N f^{1 / 2} a$ where $N=140$ is the number of DMAEMA monomers, $f$ is the condensation factor given by Manning's law $^{51}$ and $a$ is the monomer separation. For $a=2.5 \AA$, and $f=$ 0.36 one has $N f^{1 / 2} a=209 \AA$. For polystyrene sulfonate the prefactor $\alpha$ was determined to be $0.93,{ }^{52}$ here one finds $\alpha=165 /$ $209=0.8$ which sounds reasonable. This convincingly shows that the DMAEMA monomers extend so as to form a charged brush on the water side. It must be noted that the salt present in solution is not enough to contract the brush since the osmotic pressure within the brush can be calculated as being larger than the outer pressure due to the added salt. ${ }^{53}$

For $\mathrm{PS}_{48}-b-\left(\mathrm{PS}_{31}-c o\right.$-PDMAEMA 60$)$ the $q^{-2}$ asymptotic behavior (ESI Fig. $5 \dagger$ ) prompts for a diffuse corona now constituted of Gaussian chains. The same model as for $\mathrm{PS}_{50}-b$ PDMAEMA $_{140}$ was then applied with $\left\langle A_{\mathrm{s}}\right\rangle$ being represented by a

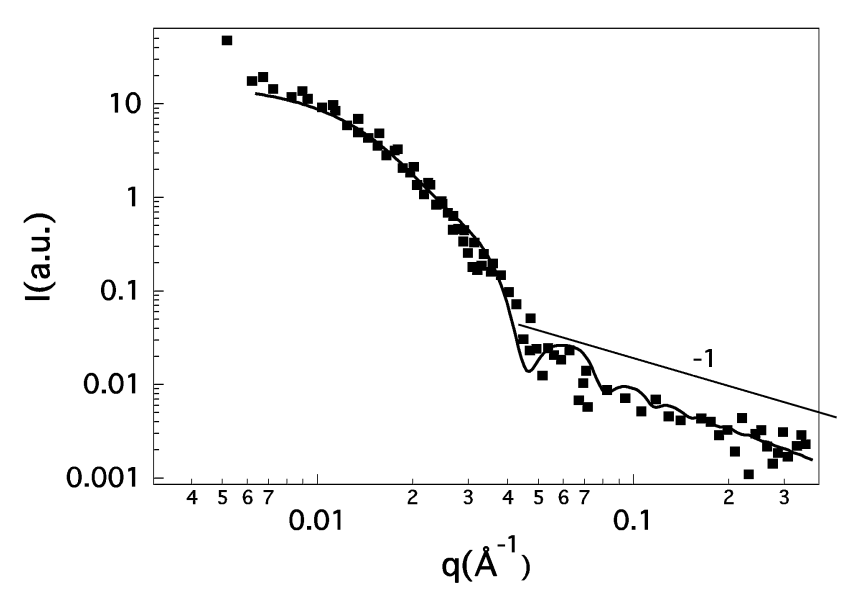

Fig. 4 Scattered intensity (squares) for the bulk contrast case of $\mathrm{PS}_{50^{-}}$ $b$-PDMAEMA $A_{140}$ at $\mathrm{pH} 1.2$ transferred from toluene to water. The continuous line is the fit to the model of a spherical charged brush described in the text. 
power-law profile in $r^{-1}$ in agreement with a Gaussian statistics of the corona and $\left\langle\delta A_{\mathrm{s}}>^{2}\right.$ being approximated by the sum of $p$ Gaussian chains of Debye form factor. ${ }^{54}$ The fit parameters are the micelle concentration, the number of chains $p$, the corona extension $L$ and the gyration radius $R_{\mathrm{g}}$ of the Gaussian chains. The two latter quantities must be in close agreement with a numerical factor of order one. Indeed the best fit (Fig. 5) gives: $L$ $=76 \AA, R_{\mathrm{g}}=65 \AA$ and $p=110$ with $R_{\mathrm{c}}=62 \AA$ in agreement with cryo-TEM. As for the diblock copolymer, an extended corona is evidenced on the water side although with a peculiar Gaussian statistics which may come from the monomer interactions between chains due to the PS hydrophobic segments. At intermediate $\mathrm{pHs}$ close to $\mathrm{p} K_{\mathrm{a}}$, the SANS intensity profiles for both contrasts and polymers are strikingly different from $\mathrm{pH} 1$. First, the signals at the two contrasts are closer than at $\mathrm{pH} 1$, especially for the $\mathrm{PS}_{50}-b$-PDMAEMA 140 copolymer where the difference is small enough to cast a doubt about the oil encapsulation in the core. Second, the sharp decrease of the signal at large wavevectors (roughly in $q^{-4}$ ) indicates the presence of a sharp interface between the polymer layer and the water. No extended corona is detected. The signal of the two copolymers at the same contrast is so close that no fit was attempted for trying to distinguish between both of them.

\section{Neutron reflectivity}

Reflectivity curves were acquired for a $\mathrm{PS}_{48}-b-\left(\mathrm{PS}_{31}\right.$-coPDMAEMA $_{60}$ ) solution in toluene on top of the water phase at an equilibrated $\mathrm{pH}$ value of 3 . Because of the $\mathrm{p} K_{\mathrm{a}}$ value, this situation is fully equivalent to the equilibrated $\mathrm{pH}$ value of 1 examined before by SANS $\left(\mathrm{pH} \ll \mathrm{p} K_{\mathrm{a}}\right)$. The reflectivity signal over the whole range of wavevectors $q$ is shown in Fig. 6 .

A characteristic fringe appears at $q \approx 0.05 \AA^{-1}$ and denotes the presence of adsorbed polymer at the interface. A fit of the signal was performed to a model of four layers where the reflectivity profile is calculated using the Abeles matrix method analogous to the Parratt ${ }^{55}$ recursion relationship for specular reflection from a stratified medium. ${ }^{56}$ The best fit result is shown in Fig. 6 and corresponds to two extremal semi-infinite

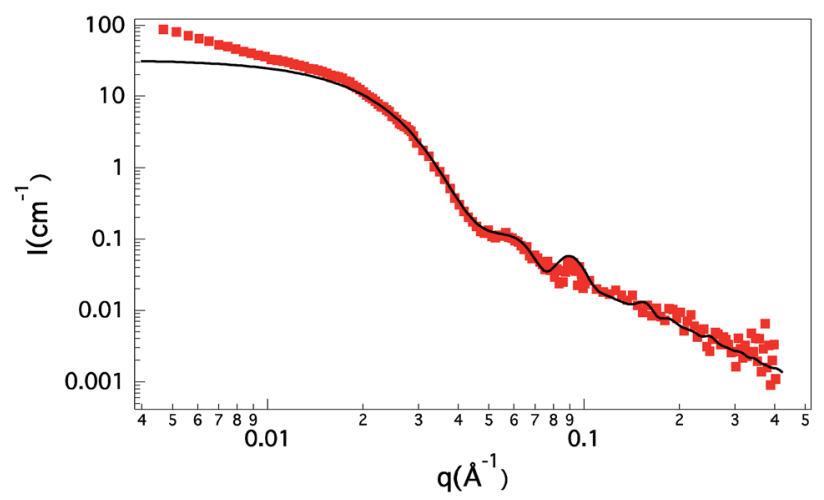

Fig. 5 Scattered intensity for the bulk contrast of the $\mathrm{PS}_{48}-b-\left(\mathrm{PS}_{31}\right.$ CO-PDMAEMA ${ }_{60}$ ) copolymer at $\mathrm{pH} 1.2$ transferred from oil to water. The continuous line is a fit of the data (squares) to the model described in the text.

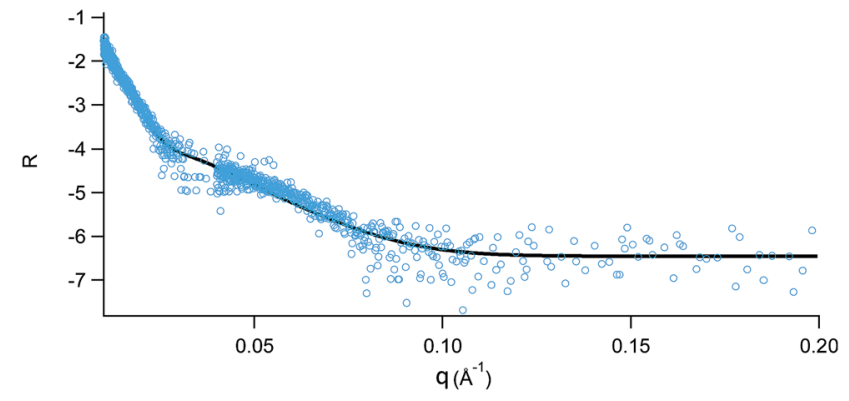

Fig. 6 Reflectivity (circles) as a function of the transfer wavevectors for the $\mathrm{PS}_{48}-b-\left(\mathrm{PS}_{31}-\mathrm{CO}-\mathrm{PDMAEMA} 60\right.$ ) copolymer at the toluene- $\mathrm{pH} 3$ water interface. The continuous line is the fit to the 4 layers model described in the text.

media of water and oil (imposed) separated by a second layer featuring the $\mathrm{PS}_{31}$-co-PDMAEMA 60 moieties on the water side and a third layer of PS on the toluene side. The latter layer is found to have a contrast density length of $4.8 \times 10^{-6} \AA^{-2}$ and an extension of $50 \AA$ with a roughness of $20 \AA$. The second layer has a contrast density length of $4.9 \times 10^{-6} \AA^{-2}$ and an extension of $59 \AA$ with a roughness of $15 \AA$. For each layer, the volume fraction of segments can be calculated from the determined contrast density length and equated to the segments volume divided by the area per chain $\boldsymbol{\aleph}$ times the layer extension. Taking into account uncertainties due to roughnesses and density length determination the area per chain is determined on the PS side to be $\boldsymbol{\kappa}=750 \pm 220 \AA^{2}$. This makes the typical distance $d$ between chains of order of the Flory radius of the PS moieties ( $R_{\mathrm{F}}=$ about $25 \AA$ ) , implying a brush conformation. The brush extension of $50 \pm 20 \AA$ favorably compares to the Auroy et al. determination $^{57}$ for a similar distance between PS chains but a different molecular weight. Their result once rescaled by the molecular weight (the brush extension is linear in the latter quantity) gives a height of $39 \AA$. On the water side the brush extension for the $\mathrm{PS}_{31}$-co-PDMAEMA 60 segments (59 $\AA$ ) nicely compares to SANS determination of $R_{\mathrm{g}}$ of the corona of $65 \AA$. The larger volume on the water side compared to the oil side is in favor of a curvature towards oil.

\section{Interfacial tension measurements}

Fig. 7 displays the equilibrium values of toluene-water interfacial tension as a function of $\mathrm{pH}$ after 24 hours of contact, with an initial concentration of the polymer in toluene of $5 \mathrm{~g} \mathrm{~L}^{-1}$.

Over the whole range of investigated $\mathrm{pH}$, all copolymers are surface-active since they decrease the interfacial tension to values lower than $35 \mathrm{mN} \mathrm{m}^{-1}$, which is the tension of the bare interface. A first set of curves for $\mathrm{PS}_{48}-b-\left(\mathrm{PS}_{31}-c o\right.$-PDMAEMA 60 , $\mathrm{PS}_{56}$ - $c 0$-PDMAEMA ${ }_{138}$ and $\mathrm{PS}_{50}-b$-PDMAEMA 140 presents similarities with a minimum at intermediate $\mathrm{pH}$ in the vicinity of their $\mathrm{p} K_{\mathrm{a}}$. Interfacial rheology measurements were conducted on $\mathrm{PS}_{48}-b$ - $\left(\mathrm{PS}_{31}-c o-\mathrm{PDMAEMA}_{60}\right)$ samples at $\mathrm{pH} 5.6$ by oscillating the rising toluene droplets at a frequency of $1 \mathrm{~Hz}$ using the pendant/rising drop tensiometer. The interface was found barely elastic with a value of the compression/dilatation elastic modulus lower than $2 \mathrm{mN} \mathrm{m}^{-1}$. With respect to chain dynamics, 


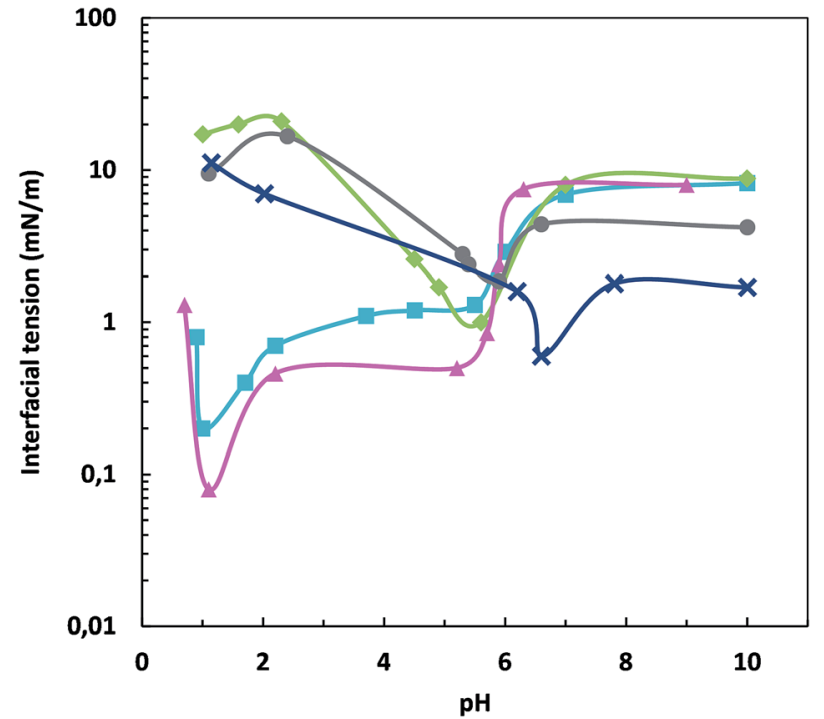

Fig. 7 Equilibrium values of toluene-water interfacial tension as a function of $\mathrm{pH}$ for each copolymer at $25^{\circ} \mathrm{C}$ after 24 hours of contact between the two phases. I: $\mathrm{PS}_{83}-b-\left(\mathrm{PS}_{54}-\mathrm{CO}-\mathrm{PDMAEMA} 128\right) ; \mathrm{\Delta}: \mathrm{PS}_{65}-b-$ $\left(\mathrm{PS}_{25}-\mathrm{CO}-\mathrm{PDMAEMA}{ }_{55}\right) ; 0: \mathrm{PS}_{48}-b-\left(\mathrm{PS}_{31}-\mathrm{CO}-\mathrm{PDMAEMA} \mathrm{A}_{60}\right) ; \mathrm{Q}: \mathrm{PS}_{50}-b-$ PDMAEMA $_{140}$; : PS $_{56}$-CO-PDMAEMA 138 .

this result shows that under these compression/dilatation conditions the polymer chains have time to rearrange at interfaces. On both sides of the minimum, adsorption at interfaces decreases since the tension increases up to $10 \mathrm{mN} \mathrm{m}^{-1}$. The second set of curves for $\mathrm{PS}_{83}-b$ - $\left(\mathrm{PS}_{54}-c o\right.$ - $\left.\mathrm{PDMAEMA}_{128}\right), \mathrm{PS}_{65}-b-$ $\left(\mathrm{PS}_{25}-\mathrm{co}\right.$-PDMAEMA $\left.{ }_{55}\right)$ also exhibits relatively low interfacial tension for $\mathrm{pH}$ values close to $\mathrm{p} K_{\mathrm{a}}$. However, a second minimum at $\mathrm{pH}$ near 1 with much lower interfacial tension values $\left(0.2 \mathrm{mN} \mathrm{m}^{-1}\right.$ for $\mathrm{PS}_{83}-b$ - $\left(\mathrm{PS}_{54}-c o\right.$-PDMAEMA $\left.{ }_{128}\right)$ and $0.08 \mathrm{mN} \mathrm{m}^{-1}$ for $\mathrm{PS}_{65}-b$ - $\left(\mathrm{PS}_{25}-c o\right.$-PDMAEMA $\left.{ }_{55}\right)$ ) is clearly visible on both curves. At $\mathrm{pH}$ close to 1 , the interfacial tension values then point to a higher interfacial coverage. As a remark, these low interfacial tension values at $\mathrm{pH}$ near 1 are observed for the polymers that transfer negligibly to water, as shown by UV spectroscopy. However, the chains adsorb at interfaces as they capture protons to provide remarkable coverage of the surface. The proton concentration at that $\mathrm{pH}$ is sufficiently high to ionize the chains, which likely protrude towards water without leaving the toluene phase. Under such a condition, the initial and final pHs are the same, equal to 1 due to protons in large excess compared to DMAEMA units. To check whether droplet sizes correlate with interfacial tension values, the average droplet (oil or water) diameter (obtained by measuring size of 100 droplets by optical microscopy) was plotted as a function of the interfacial tension for all copolymers over the whole range of pH (Fig. 8).

Results show that low tensions give emulsion droplets with smaller sizes, as expected since low interfacial tension values decrease the energy cost to create interfaces at constant encapsulated volume. Remarkably, droplets with diameters lower than 3 micrometers are indeed obtained for $\mathrm{PS}_{83}-b$ - $\left(\mathrm{PS}_{54^{-}}\right.$ $c o$-PDMAEMA $\left.{ }_{128}\right)$ and $\mathrm{PS}_{65}-b-\left(\mathrm{PS}_{25}-c o\right.$-PDMAEMA $\left.{ }_{55}\right)$ at acidic $\mathrm{pH}$

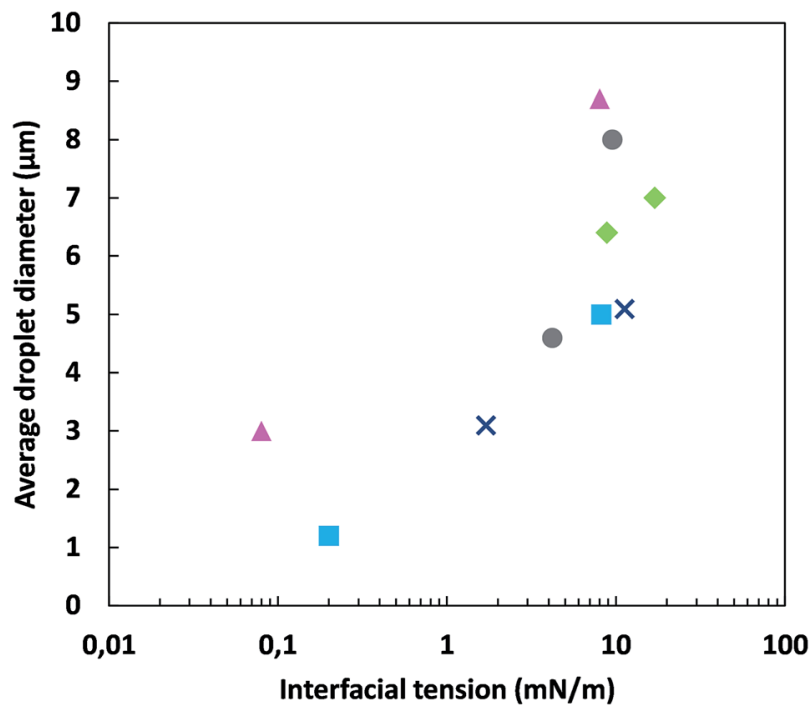

Fig. 8 Average droplet diameter of emulsion droplets (direct and inverse) versus interfacial tension values for the corresponding $\mathrm{pH}$ at $25^{\circ} \mathrm{C}$. The oil and water phases were left into contact for $24 \mathrm{~h}$ at $25^{\circ} \mathrm{C}$ prior to emulsification. II: $\mathrm{PS}_{83}-b-\left(\mathrm{PS}_{54}-\mathrm{CO}-\mathrm{PDMAEMA} 128\right) ; \mathrm{\Delta}: \mathrm{PS}_{65}-b-$ $\left(\mathrm{PS}_{25}-\mathrm{CO}-\mathrm{PDMAEMA}{ }_{55}\right) ; \mathrm{Q}: \mathrm{PS}_{48}-b-\left(\mathrm{PS}_{31}-\mathrm{CO}-\mathrm{PDMAEMA} \mathrm{A}_{60}\right) ; \mathrm{PS} \mathrm{P}_{50}-b-$ $\mathrm{PDMAEMA}_{140}$; : $\mathrm{PS}_{56}$-CO-PDMAEMA 138 .

near 1 for which the interfacial tension decreases to 0.2 and $0.08 \mathrm{mN} \mathrm{m}^{-1}$ respectively. Overall, the experimental observations reported here clearly established that $\mathrm{pH}$ changes provide various interfacial coverages and control of emulsion size (Fig. 7 and 8), in accordance with the copolymer composition and structure.

\section{Emulsion type and stability}

The type of emulsion was then investigated as a function of $\mathrm{pH}$ and copolymer composition. In the light of these results, we aim at establishing correlations between the emulsion type and stability and the conformation of the adsorbed polymer chains with respect to their environment $(\mathrm{pH})$, structure and composition. This conformation should determine the spontaneous curvature at the oil-water interface and possibly differentiate between the polymer behaviors.

The confocal microscopy images of water-toluene emulsions stabilized by each of the five copolymers are presented in Fig. 9: $\mathrm{PS}_{83}-b-\left(\mathrm{PS}_{54}-c o-\mathrm{PDMAEMA}_{128}\right), \quad \mathrm{PS}_{65}-b-\left(\mathrm{PS}_{25}-c o\right.$-PDMAEMA $\left.{ }_{55}\right)$, $\mathrm{PS}_{48}-b-\left(\mathrm{PS}_{31}-c o\right.$-PDMAEMA $\left.{ }_{60}\right), \mathrm{PS}_{56}-c o$-PDMAEMA ${ }_{138}$ and $\mathrm{PS}_{50}-b-$ PDMAEMA $_{140}$.

An appropriate amount of an hydrophobic fluorescent dye (Nile Red) was added to toluene right before emulsification so that the oil phase appears in red color in the pictures. Three different behaviors with respect to the emulsion kind can be distinguished (Fig. 9).

First, both $\mathrm{PS}_{56}-c o$-PDMAEMA ${ }_{138}$ and $\mathrm{PS}_{50}-b$-PDMAEMA ${ }_{140}$ give the $\mathrm{O} / \mathrm{W}(\mathrm{pH}$ near 1$) \leftrightarrow$ "unstable" emulsions ( $\mathrm{pH}$ near $\mathrm{p} K_{\mathrm{a}}$ ) $\leftrightarrow \mathrm{W} / \mathrm{O}(\mathrm{pH} \approx 7-8)$ generic sequence with changing $\mathrm{pH}$ (Fig. 9, pictures a-f). For the diblock copolymer, the UV data presented in Fig. 2 show that the Bancroft rule can be applied to predict 


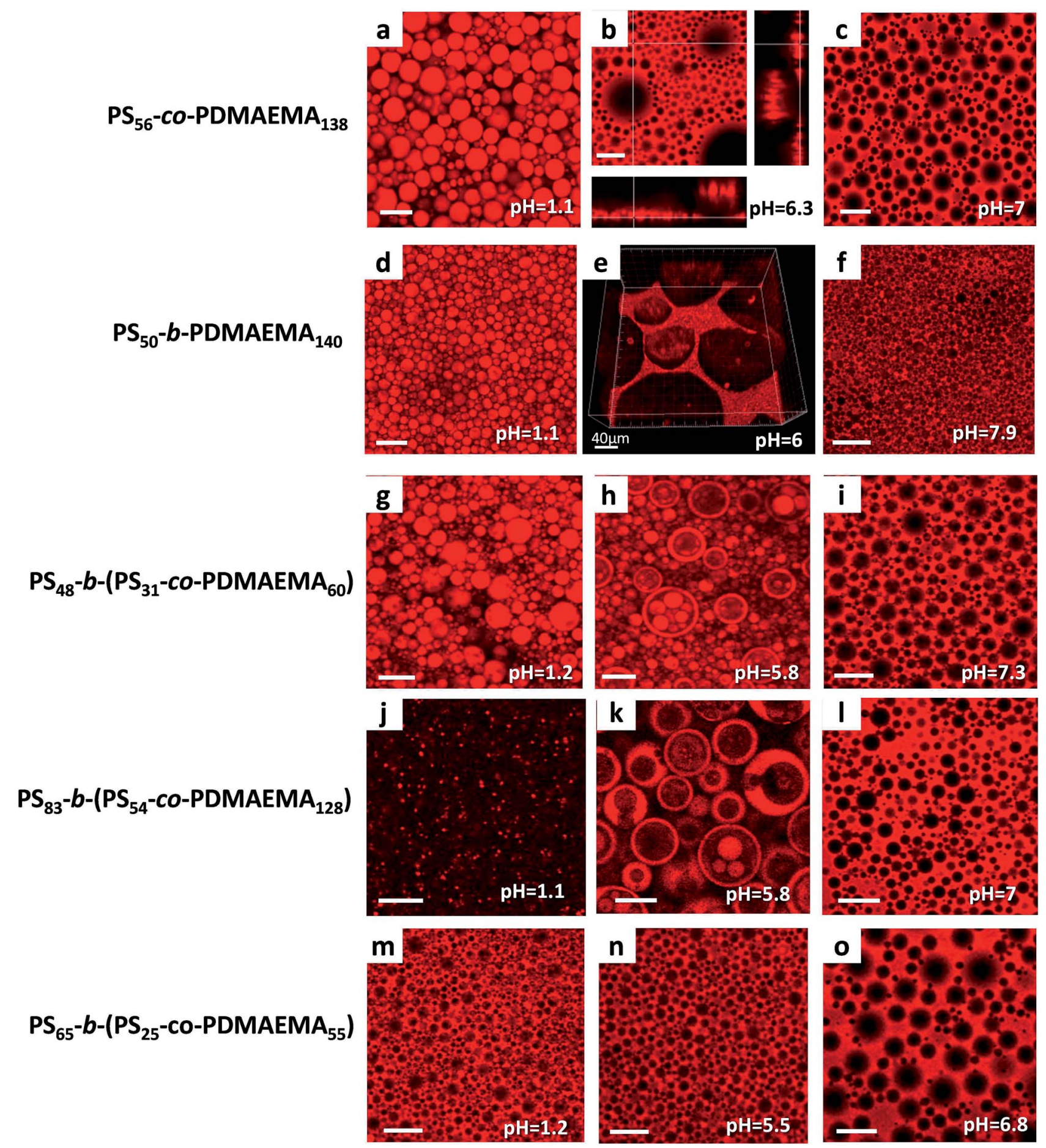

Fig. 9 Fluorescent confocal microscopy images of water-toluene $(50 / 50 \mathrm{v} / \mathrm{v})$ emulsions stabilized with each copolymer with varying $\mathrm{pH}$ as labeled at $25^{\circ} \mathrm{C}$. The oil phase fluoresces red because of addition of Nile Red $\left(10^{-3} \mathrm{M}\right)$ before shearing in toluene. The scale bar represents $20 \mu \mathrm{m}$.

the emulsion type with a chain transfer of $60 \%$ and $0 \%$ at $\mathrm{pH} 1.1$ and 7 respectively. The presence of toluene in water microemulsions at $\mathrm{pH} 1.2$ and 6.2 allows investigating the conformation of $\mathrm{PS}_{50}-b$-PDMAEMA 140 chains at toluene-water interfaces. At $\mathrm{pH} 1.2$, toluene swollen spherical micelles with a core radius of about $8 \mathrm{~nm}$ were observed (averaging cryo-TEM and SANS measurements). The curvature towards oil of the adsorbed chains is then positive. This is normal since the micelle corona is stretched as revealed by the SANS high $q$ 's asymptotic behavior, which scales with a $q^{-1}$ power law, and occupy a much larger volume than the PS moieties in toluene. The emulsion type under acidic conditions, O/W (Fig. 9, picture d), is then in agreement with the structure formed at equilibrium (direct microemulsions). At $\mathrm{pH}$ higher than 7 , the chains 
do not transfer to water (UV data) but still adsorb at the interface as viewed by tensiometry and stabilize W/O emulsions (Fig. 9, picture f). At $\mathrm{pH}$ slightly lower than the region of phase inversion, near $\mathrm{pH}=6$, the formation of $\mathrm{O} / \mathrm{W}$ microemulsions is still observed with a hydrophobic core size of $4 \mathrm{~nm}$ (on average from cryo-TEM and SANS). The polymer chains hence form structures curved towards oil at $\mathrm{pH}$ of unstable emulsions but SANS results evidence a more compact polymer corona. This is in agreement with a curvature of the chains going to zero in this region of inversion. However, the formation of bicontinuous structures was never observed as it would be the case for surfactants, The flatter conformation coincides with a higher interfacial coverage as shown by low interfacial tension values around $1 \mathrm{mN} \mathrm{m}^{-1}$. Interestingly, in the $\mathrm{pH}$ range of unstable emulsions, the partitioning is in the $46-51 \%$ range and both polymers (diblock and statistical) provide emulsions with stability good enough to allow for the observation of coexisting $\mathrm{O} / \mathrm{W}$ and $\mathrm{W} / \mathrm{O}$ emulsions with the lifetime typically not exceeding one hour. Both types of droplets were indeed observed as shown by the $3 \mathrm{D}$ reconstructions of images that evidence the creaming and sedimentation of oil and water droplets at the top and bottom of the quartz cell respectively (Fig. 9, picture e). Such a behavior was never observed for emulsions stabilized by surfactants but was reported for particles coated with adsorbed diblock copolymer chains. ${ }^{58}$

For the $\mathrm{PS}_{56}-\mathrm{co}$-PDMAEMA ${ }_{138}$ copolymer under acidic conditions, $64 \%$ of the copolymer chains transfer to water while at $\mathrm{pH}$ larger than $\mathrm{p} K_{\mathrm{a}} 6.8$, less than $5 \%$ of the copolymer chains transfer from toluene to water (Fig. 2). Overall, these results, which are in good agreement with the Bancroft rule, point also to a behavior similar to $\mathrm{C}_{\mathrm{i}} \mathrm{E}_{\mathrm{j}}$ surfactants. Here, the absence of microemulsions prevents any direct information about the conformation at interfaces to be obtained by SANS. Although not detailed here, dynamic light scattering measurements in the water phase at $\mathrm{pH} 1.2$ were performed to probe chain conformation in the bulk. The size of the $\mathrm{PS}_{56}{ }^{-} \mathrm{Co}$-PDMAEMA 138 chains, $R_{\mathrm{h}}=5.8 \mathrm{~nm}$ was found to be quite close to that of the PDMAEMA $_{206}, R_{\mathrm{h}}=6.2 \mathrm{~nm}$. With Flory radii $\left(a N^{3 / 5}\right.$, with $a=$ $0.25 \mathrm{~nm}$ ) of 5.9 and $6.1 \mathrm{~nm}$ for the $\mathrm{PS}_{56}-$ Co-PDMAEMA 138 and PDMAEMA $_{206}$ polymers respectively, both types of chains are unassociated and under good solvent conditions at $\mathrm{pH}$ 1.2. We suggest that the chain segments at the oil/water interface under acidic conditions form loops with a favored extension towards water over toluene due to the presence of positively charged DMAEMA units that brings some of the styrene units on the water side. On the basis of surfactant curvature arguments, this would lead to the formation of $\mathrm{O} / \mathrm{W}$ emulsions, as it is indeed the case (Fig. 9, picture a). At basic $\mathrm{pH}$, the neutral chains cover the interface with a majority of chain segments on the oil side as water and toluene are poor and good solvents of the polymer respectively. Inverse emulsions are then stabilized in the range of basic $\mathrm{pH}$ (Fig. 9, picture c). At intermediate $\mathrm{pH}$ near $\mathrm{p} K_{\mathrm{a}}$, the partial protonation of the DMAEMA units would lead to a fair partitioning of the chain segments at the interface and hence, to a near zero curvature and unstable emulsions (Fig. 9, picture b). With a decrease of the interfacial tension at $\mathrm{pH}$ near 6 to $2 \mathrm{mN} \mathrm{m}^{-1}$, the coverage of the interface by the chains is slightly improved as compared to that observed under both acidic and basic conditions.

A different behavior is observed with $\mathrm{PS}_{83}-b-\left(\mathrm{PS}_{54}-\mathrm{co}\right.$ PDMAEMA $\left._{128}\right)$ and $\mathrm{PS}_{48}-b$ - $\left(\mathrm{PS}_{31}\right.$-co-PDMAEMA 60 ) where we have $\mathrm{O} / \mathrm{W}$ (pH about 1) $\leftrightarrow$ multiple emulsions ( $\mathrm{pH}$ near 6) $\leftrightarrow \mathrm{W} / \mathrm{O}$ ( $\mathrm{pH}$ close to 7) upon sweeping $\mathrm{pH}$ (Fig. 9, pictures g-l). Multiple emulsions are water continuous with mixed simple $(\mathrm{O} / \mathrm{W})$, double $\mathrm{W} / \mathrm{O} / \mathrm{W}$ and complex ...W/O/W structures (Fig. 9, pictures $\mathrm{h}$ and $\mathrm{k})$. The $\mathrm{PS}_{48}-b$-( $\mathrm{PS}_{31}-c o$-PDMAEMA 60 ) polymer stabilizes inverse emulsions at $\mathrm{pH}$ higher than 6.5 (Fig. 9, picture i). A few chains, less than $10 \%$, transfer to water and the copolymer decreases the interfacial tension to values near $10 \mathrm{mN} \mathrm{m}^{-1}$. As expected, the good anchoring of the polymer at interfaces combined with a marked affinity of the chains for the toluene phase induces the formation of stable inverse emulsions in this range of basic $\mathrm{pH}$. The polymer then exhibits no difference with those described above under same $\mathrm{pH}$ conditions. By decreasing $\mathrm{pH}$ to values between 5 and $6.5\left(\mathrm{p} K_{\mathrm{a}}\right)$, we observed a decrease of the interfacial tension through a minimum to values as low as $1 \mathrm{mN} \mathrm{m}^{-1}$, an increase in the transfer to water of the chain of about $35 \%$ and the formation of stable water continuous ...W/O/W multiple emulsions (Fig. 9, picture $\mathrm{h}$ ). At $\mathrm{pH}$ below 5 , the interfacial tension increases up to values of the order of $10 \mathrm{mN} \mathrm{m} \mathrm{m}^{-1}$, the water transfer slightly increases up to $39 \%$ at most and direct (simple) emulsions form upon emulsification (Fig. 9, picture g). Hence, the formation of both multiple and direct emulsions points to an anti-Bancroft behavior. SANS measurements show that $\mathrm{O} / \mathrm{W}$ microemulsions form in the aqueous phase at $\mathrm{pH} 5.5$ and 1.2 in the form of toluene-swollen spherical micelles with hydrophobic core radii of about 4 and $6.5 \mathrm{~nm}$ respectively. At $\mathrm{pH} 1$ the hydrophilic block of $\mathrm{PS}_{48}-b-\left(\mathrm{PS}_{31}-c o\right.$-PDMAEMA 60 exhibits an original Gaussian statistics $\left(q^{-2}\right)$ with an extended corona confirming the curvature oriented towards oil. However, the local Gaussian statistic of the corona chains is disputable since $\mathrm{PS}_{31}$-coPDMAEMA $_{60}$ is under good solvent conditions at $\mathrm{pH} 1$, as previously discussed. Hence, the $q^{-2}$ asymptotic behavior may arise from the presence of $S$ units among DMAEMA units that form hydrophobic $S$ clusters within the corona and prevent the expected $q^{-1}$ rod chain extension due to excluded volume effects. At $\mathrm{pH}$ values giving rise to multiple emulsions, a $q^{-4}$ behavior is observed pointing to a compact sharp interface between the adsorbed polymer and water and consistent with a zero curvature at inversion. Like for $\mathrm{PS}_{50}-b$-PDMAEMA ${ }_{140}$, we did not observe bicontinuous microemulsions.

Upon sweeping $\mathrm{pH}$, the $\mathrm{PS}_{83}-b$ - $\left(\mathrm{PS}_{54}-c o\right.$-PDMAEMA 128$)$ polymer gives a phase inversion sequence identical to that of the $\mathrm{PS}_{48}-b$-( $\mathrm{PS}_{31}$-co-PDMAEMA 60 ) (Fig. 9 pictures $\left.\mathrm{j}-\mathrm{l}\right)$. The two polymers differ only in their total molar masses since their block length and $\mathrm{S}$ to DMAEMA unit ratios are similar. This sole difference induces interesting dissimilarities. First, UV measurements show that the chains transfer is lower than $5 \%$ over the whole $\mathrm{pH}$ range (Fig. 2). This probably comes from too high a PS block length and/or too high a total molar mass. Within the framework of the Bancroft rule, such a behavior would certainly call for the exclusive formation of inverse emulsions, which is indeed not the case (Fig. 9 pictures $\mathrm{j}$ and k). 
Contrarily to its smaller $\mathrm{PS}_{48}-b$ - $\left(\mathrm{PS}_{31}\right.$-co-PDMAEMA 60$)$ sibling, no quantitative information related to conformation (SANS) and curvature (SANS, cryo-TEM) can be obtained for this polymer as chains remain mostly in toluene. Here also the development of liquid-liquid neutron reflectivity is promising as it would provide this fundamental information for polymers like $\mathrm{PS}_{83}-b$ $\left(\mathrm{PS}_{54}\right.$-co-PDMAEMA $\left.{ }_{128}\right)$, otherwise not accessible by other techniques.

The variation of the interfacial tension with $\mathrm{pH}$ presents a minimum of about $0.2 \mathrm{mN} \mathrm{m}^{-1}$ at $\mathrm{pH}$ about 1 , a feature that is shared only with $\mathrm{PS}_{65}-b$ - $\left(\mathrm{PS}_{25}-c o\right.$-PDMAEMA 55$)$, as discussed below (Fig. 7). The interface coverage is then even better at $\mathrm{pH}$ near 1 than at $\mathrm{pH}$ close to 6 where multiple emulsions form.

A third type of behavior is provided by the $\mathrm{PS}_{65}-b-\left(\mathrm{PS}_{25}-\mathrm{CO}\right.$ PDMAEMA $_{55}$ ) polymer with the biggest PS/PDMAEMA ratio that leads exclusively to the formation of inverse emulsions over the whole $\mathrm{pH}$ range (Fig. 9 pictures $\mathrm{m}-\mathrm{o}$ ). Regarding the structure, it compares interestingly with $\mathrm{PS}_{48}-b-\left(\mathrm{PS}_{31}\right.$-co-PDMAEMA 60$)$ as they have almost the same total molar mass and differ essentially from the length of the PS block and the ratio of blocks (Table 1). The overall molar styrene content, 0.66, which is higher than that of the other polymers (for instance, $\mathrm{S}$ content of $\mathrm{PS}_{48}-b$-( $\mathrm{PS}_{31}$-co-PDMAEMA 60 is 0.56$)$ and the long hydrophobic PS block (65 S units) are decisive factors since the $\mathrm{PS}_{65}-b$ $\left(\mathrm{PS}_{25}\right.$-co-PDMAEMA $\left.{ }_{55}\right)$ chains transfer only slightly to water $(<11 \%)$ as compared to $\mathrm{PS}_{48}-b-\left(\mathrm{PS}_{31}\right.$-co-PDMAEMA 60$)(<39 \%)$ at $\mathrm{pH}$ 1. This makes a big change as $\mathrm{PS}_{65}-b-\left(\mathrm{PS}_{25}-c o-\mathrm{PDMAEMA}_{55}\right)$ follows the Bancroft rule, in contrast to $\mathrm{PS}_{48}-b-\left(\mathrm{PS}_{31}-\mathrm{co}\right.$ PDMAEMA $_{60}$ ). Regarding interfacial conformation, the number of charged DMAEMA units (high S content) is not sufficiently high to bring enough monomer units on the water side even at $\mathrm{pH} 1$, therefore favoring extension of the chain towards oil irrespective of $\mathrm{pH}$, justifying inverse emulsion within the concept of curvature. This is in deep contrast with the $\mathrm{PS}_{48}-b$ $\left(\mathrm{PS}_{31}\right.$-co-PDMAEMA 60 ) polymer that has enough DMAEMA units to provide larger chain extension on the water side (positive curvature) and form direct instead of inverse emulsions. The surface activity of the chains is large as shown from the interfacial tension data, which shows again an interfacial tension minimum with a value of $0.08 \mathrm{mN} \mathrm{m}^{-1}$ at $\mathrm{pH}$ near 1 (Fig. 7).

\section{Discussion}

We have highlighted four original characteristics of the transitional emulsion phase inversion using copolymers with different structures and compositions, and $\mathrm{pH}$ as a stimulus:

(1) The curvature of several polymer chains was determined by SANS or reflectivity. In all cases under scrutiny, the curvature sign deduced from the respective volumes occupied on oil and water sides is in agreement with the emulsion kind.

(2) Both anti-Bancroft and Bancroft behavior were observed using the same polymer under different conditions or different polymers under the same conditions.

(3) The $\mathrm{pH}$ (stimulus) dependence of the interfacial tension presents an original signature with either one or two minima as $\mathrm{pH}$ is swept to induce the transitional emulsion phase inversion sequence.
(4) The crossover from direct to inverse emulsions was covered by two different routes: the first one involves the formation of coexisting inverse and direct transient emulsions and the second one occurs through the formation of watercontinuous multiple emulsions.

All these features, which are directly related to polymer structures and compositions and to their use in the given environment, are now discussed.

(1) The large extension of $\mathrm{PS}_{48}-b-\left(\mathrm{PS}_{31}-c o-\mathrm{PDMAEMA}_{60}\right)$ and $\mathrm{PS}_{50}-b$-PDMAEMA 140 corona with respect to the oil core dimension at acidic pHs demonstrates a positive curvature of the chain at the microemulsion level. This is always in agreement with direct emulsion formation $(\mathrm{O} / \mathrm{W})$ whatever the Bancroft behavior. At intermediate pHs the curvature is observed to go to zero (most convincingly for $\mathrm{PS}_{48}-b-\left(\mathrm{PS}_{31}-c o\right.$-PDMAEMA 60$)$ ) but direct microemulsions are still formed in accordance with the formation of direct multiple emulsions, again invalidating the Bancroft rule. Reflectivity at the oil-water interface is in full agreement with the SANS determination.

About (2), two polymers were identified, namely $\mathrm{PS}_{48}-b-\left(\mathrm{PS}_{31^{-}}\right.$ $c o$-PDMAEMA 60 ) and $\mathrm{PS}_{83}-b$ - $\left(\mathrm{PS}_{54}\right.$ - $c o$-PDMAEMA 128$)$ that exhibit an anti-Bancroft behavior. It occurs when they present conflicting situation with respect to their oil-water partitioning and conformation (curvature) at interfaces: the latter parameter is more decisive to predict emulsion kinds. Their structure and composition are close with $N_{1} / N=0.35$ and $0.31, N_{1} / N_{2}=0.53$ and 0.46 , styrene content of 0.57 and 0.52 for $\mathrm{PS}_{48}-b-\left(\mathrm{PS}_{31}-\mathrm{co}\right.$ PDMAEMA $\left._{60}\right)$ and $\mathrm{PS}_{83}-b$-( $\mathrm{PS}_{54}-c o$-PDMAEMA $\left.{ }_{128}\right)$ respectively. However, their total average molar masses are in a ratio of 2 $(N=139$ and 265). Consequently, at given $\mathrm{pH}$, we can reasonably argue that they are likely to have similar curvatures but different toluene-water partitioning as the energy cost to transfer a chain from oil to water depends tightly on chain length. Clearly, our polymer emulsification conditions do not meet the conditions under which violations to the Bancroft rule were observed for surfactants. ${ }^{19}$ In contrast, we observe violation of Bancroft's law with respect to the emulsion type for stable emulsions and in the presence of aggregates, i.e. at concentrations higher than cmcs of polymers.

At $\mathrm{pH}$ around 1, the protonation of the DMAEMA units promotes a larger volume occupied by the chain on the water side than on the oil side. This is clearly shown by SANS $\left(q^{-2}\right)$ and cryo-TEM (oil-swollen micelles) experiments and correlates well with the formation of direct emulsions. The longer $\mathrm{PS}_{83}-b-\left(\mathrm{PS}_{54}{ }^{-}\right.$ co-PDMAEMA - $_{128}$ ) produces an outstanding anti-Bancroft behavior since the polymer concentration in water is near zero and the small size (diameter of about 1 micrometer) toluene droplets are quite stable (over months). By comparison, the anti-Bancroft behavior of $\mathrm{PS}_{48}-b$-( $\mathrm{PS}_{31}-c o$-PDMAEMA $\left.{ }_{60}\right)$ is softer since the water partitioning almost reaches $40 \%$ with oil droplet diameters of about 6 micrometers.

At $\mathrm{pH}$ higher than $\mathrm{p} K_{\mathrm{a}}\left(6.5\right.$ for $\mathrm{PS}_{48}-b-\left(\mathrm{PS}_{31}-\mathrm{co}\right.$-PDMAEMA 60$)$, not known for $\mathrm{PS}_{83}-b-\left(\mathrm{PS}_{54}-c o\right.$-PDMAEMA $\left.\left.{ }_{128}\right)\right)$, the polymer chains are mostly in the toluene phase. With the formation of inverse emulsion, both polymers follow the Bancroft's law.

By increasing the length of the PS block of $\mathrm{PS}_{48}-b-\left(\mathrm{PS}_{31}-\mathrm{Co}-\right.$ PDMAEMA $\left._{60}\right)$, we synthesized the $\mathrm{PS}_{65}-b-\left(\mathrm{PS}_{25}-\mathrm{co}-\mathrm{PDMAEMA}_{55}\right)$ 
polymer $\left(N_{1} / N_{2}=0.81 ; N_{1} / N=0.45\right.$; and styrene overall content 0.62). The extension of the PS block gives spectacular changes since the partitioning is strongly displaced in favor of oil (UV data) in a way similar to that of $\mathrm{PS}_{83}-b$ - $\left(\mathrm{PS}_{54}-c o\right.$-PDMAEMA $\left.{ }_{128}\right)$. However, $\mathrm{PS}_{65}-b$ - $\left(\mathrm{PS}_{25}-c o\right.$-PDMAEMA $\left.{ }_{55}\right)$ stabilizes inverse emulsions and hence, follows the Bancroft rule. This can be reasonably attributed to a better global extension of the chain towards the toluene side over the water side, as compared to the two other polymers $\left(\mathrm{PS}_{83}-b-\left(\mathrm{PS}_{54}-c o\right.\right.$-PDMAEMA 128$)$ and $\mathrm{PS}_{48}-b$ $\left(\mathrm{PS}_{31}-c o\right.$-PDMAEMA 60$)$ ).

About (3), our contribution also provides an original route to the achievement of low interfacial tension at the oil-water interface. According to our results, obtained at $\mathrm{pH}$ near 1 for the $\left(\mathrm{PS}_{65}-b-\left(\mathrm{PS}_{25}-c o-\mathrm{PDMAEMA}_{55}\right)\right.$ and $\mathrm{PS}_{83}-b-\left(\mathrm{PS}_{54}-c o-\right.$ PDMAEMA $_{128}$ ) polymers, a simple strategy for reaching such low tensions can be derived. It consists, for a given oil, of adjusting the polymer emulsifier structure and composition to the formulation constraints $(\mathrm{pH}, T, \ldots)$. The general idea is to drive the chain transfer from one phase (phase 1: oil in our case) to the interface while avoiding chain transfer to the other phase, initially free of macromolecules (phase 2: here, water). The latter condition can be realized by choosing polymers with sufficiently high molar mass or adjusted hydrophobicity (increasing the length of the PS block for instance). The accumulation of polymer chains at interfaces is triggered by a stimulus ( $\mathrm{pH}$ in our case) from phase 2 (water). As they can hardly cross the interface, the trapped chains accumulate and pack leading to low interfacial tensions. The effect is lost as chain transfer proceeds even partially (from phase 1, toluene to phase 2, water) as seen from the interfacial tension versus $\mathrm{pH}$ curves of $\mathrm{PS}_{48^{-}} b-\left(\mathrm{PS}_{31^{-}}-c o-\mathrm{PDMAEMA}_{60}\right)$ and $\mathrm{PS}_{83^{-}} b-\left(\mathrm{PS}_{54^{-}}-c 0^{-}\right.$ PDMAEMA $_{128}$ ). The latter displays an abrupt change in the $\mathrm{pH}$ range of near zero curvature and possesses a minimum in the $\mathrm{pH}$ range of non-zero curvature, while the former polymer exhibits a single near zero curvature minimum. It is worth noting that low interfacial tension values are found in the region of non-zero curvature (either positive with $\mathrm{PS}_{83}-b-\left(\mathrm{PS}_{54^{-}}\right.$ $c o$-PDMAEMA 128$)$ or negative for $\mathrm{PS}_{65}-b$ - $\left(\mathrm{PS}_{25}\right.$-co-PDMAEMA 55$)$ as compared to surfactants, which indeed show very low interfacial tensions but only at nearly zero curvature..$^{59,60}$

Regarding (4), our work shows that multiple emulsions are obtained for two polymers, $\mathrm{PS}_{48}-b$ - $\left(\mathrm{PS}_{31}\right.$-co-PDMAEMA $\left.{ }_{60}\right)$ and $\mathrm{PS}_{83}-b$ - $\left(\mathrm{PS}_{54}-c o\right.$-PDMAEMA $\left.{ }_{128}\right)$, in the region of phase inversion, which means that (A) the interfacial tension is sufficiently low and that (B) polymer conformation shows a comparable extension of the chain segments on both sides of the interface (near zero curvature). Note that the first condition is not sufficient because the low interfacial tensions measured at $\mathrm{pH} 1$ for $\mathrm{PS}_{83^{-}}$ $b$-( $\mathrm{PS}_{54}-c o$-PDMAEMA $\left.{ }_{128}\right)$ and $\mathrm{PS}_{65}-b$ - $\left(\mathrm{PS}_{25}-c o\right.$-PDMAEMA $\left.{ }_{55}\right)$ lead to the formation of $\mathrm{O} / \mathrm{W}$ and $\mathrm{W} / \mathrm{O}$ emulsions respectively and not to multiple emulsions. The (A) and (B) conditions are also fulfilled by the $\mathrm{PS}_{50}-b$-PDMAEMA 140 and $\mathrm{PS}_{56}-c o$-PDMAEMA ${ }_{138}$ copolymers. However, rather than forming multiple emulsions, these copolymers stabilize coexisting water and oil droplets. Our results then suggest that the formation of multiple emulsions may require a third condition associated with an antiBancroft behavior (discussed above at $\mathrm{pH} 1$ but also valid at intermediate $\mathrm{pH}$ ), in addition to the (A) and (B) conditions. About conformation, it is worth noting that $\mathrm{PS}_{50}-b$ -

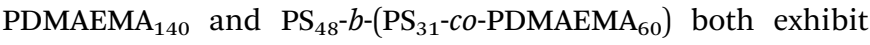
rather compact conformations at $\mathrm{pH}$ close to $\mathrm{p} K_{\mathrm{a}}$ with very minor differences (SANS results). At this stage of the analysis, the conformation does not seem to be the decisive factor promoting multiple emulsions.

We suggest the following very tentative scenario for the making of the multiple emulsions. At $\mathrm{pH}$ near $\mathrm{p} K_{\mathrm{a}}$ (about 6), upon emulsification of equal volume of oil and water, the turbulent flow of the ultra Turrax produces a bicontinuous phase of oil and water made of connected domains. Indeed all polymers discussed above, except $\mathrm{PS}_{65}-b$ - $\left(\mathrm{PS}_{25}-c o\right.$-PDMAEMA $\left.{ }_{55}\right)$, exhibit a close-to-zero curvature able to stabilize transient bicontinuous structures. When mixing stops, coarsening of these domains may form tube-like domains like in phase separation of liquids. ${ }^{61}$ If a polymer is symmetrically partitioned between water and oil like that for $\mathrm{PS}_{50}-b$-PDMAEMA ${ }_{140}$ and $\mathrm{PS}_{56}$-co-PDMAEMA ${ }_{138}$, a symmetric transient situation of $\mathrm{O} / \mathrm{W}$ and W/O mixture arises whose stability is large enough because of zero curvature of the adsorbed polymer and low surface tension. For $\mathrm{PS}_{48^{-}}-b-\left(\mathrm{PS}_{31}-c o-\mathrm{PDMAEMA}_{60}\right)$ and $\mathrm{PS}_{83}-b-\left(\mathrm{PS}_{54}-c o-\right.$ PDMAEMA $_{128}$ ) copolymers, the polymer is only present in oil. This may break the symmetry of tube fragmentation, leading to a fully discontinuous oil phase with nested water droplets. More quantitatively, a tube of liquid is unstable because of PlateauRayleigh instability where the capillary pressure of more curved zones drives the flow towards less curved zones. Oil tubes are, however, also prone to osmotic pressure of the polymer which may oppose instability and break the symmetry. Water domains would fragment first, forming the innermost drops. The water continuous phase is, however, favored since a majority of outer charged segments still maximizes counterions entropy. In a slightly different context, differences in viscosities for 2D phase separating interconnected domains were shown to induce nested domains as domains coarsen with time. ${ }^{62}$ In our case we believe that viscosities are not different enough to make such a mechanism relevant.

\section{Conclusions}

A very precise definition of the polymer architecture is needed to design polymers able to form stimulable emulsions. The requirements mix the ability to reach a flat, compact conformation at the oil-water interface with a close to zero spontaneous curvature and the dissymmetry of partitioning between the phases. Too hydrophilic polymers would partition equally, leading to a behavior close to the one of the surfactants. Too hydrophobic polymers only stabilize inverse $\mathrm{W} / \mathrm{O}$ emulsions because protonation is too weak. So far, none of the polymers is able to stabilize multiple emulsions with a continuous oil phase. This is probably linked to the strongest effect of electrostatic interactions: even a few protonated segments promote a slightly positive curvature. The next step we foresee is to vary the polymer architecture to vary the $\mathrm{pH}$ window where multiple emulsions can be formed and to explore the possibility of forming nanoemulsions with such polymers. 


\section{Acknowledgements}

The authors would like to thank the "Service de Microscopie Electronique, Institut de Biologie Paris-Seine (CNRS-UPMC)" and especially Mme Frébourg for her kind assistance in the cryo-TEM experiments. We warmly thank Richard Campbell, Giovanna Fragneto and Eric Watkins for their kind assistance on Figaro reflectometer at ILL. We thank the RTRA Triangle de la Physique for its funding through the Imagemul project.

\section{Notes and references}

1 M. Machado, M. R. Bronze and H. Ribeiro, J. Cosmet. Dermatol., 2007, 6, 239.

2 F. Leal-Calderon, S. Homer, A. Goh and L. Lundin, Food Hydrocolloids, 2012, 27, 30.

3 J. L. Salager and A. M. Forgiarini, Energy Fuels, 2012, 26, 4027.

4 M. Gallarate, M. E. Carlotti, M. Trotta and S. Bovo, Int. J. Pharm., 1999, 188, 233.

5 D. J. McClements, Curr. Opin. Colloid Interface Sci., 2012, 17, 235.

6 Multiple Emulsions: Technology and Applications, ed. A. Aserin, Wiley-Interscience, 2007.

7 F. Michaut, P. Hebraud and P. Perrin, Polym. Int., 2003, 52, 594.

8 K. Lindenstruth and B. W. Muller, Eur. J. Pharm. Biopharm., 2004, 58, 621.

9 S. C. Yu, A. Bochot, G. Le Bas, M. Cheron, J. Mahuteau, J. L. Grossiord, M. Seiller and D. Duchene, Int. J. Pharm., 2003, 261, 1.

10 K. Miyazawa, I. Yajima, I. Kaneda and T. Yanaki, J. Cosmet. Sci., 2000, 51, 239.

11 C. M. Fox, Cosmet. Toiletries, 1986, 101, 101.

12 G. Muschiolik, Curr. Opin. Colloid Interface Sci., 2007, 12, 213.

13 A. Kabalnov and H. Wennerström, Langmuir, 1996, 12, 276.

14 V. Butun, S. P. Armes and N. C. Billingham, Polymer, 2001, 42, 5993.

15 S. H. Yuk, S. H. Cho and S. H. Lee, Macromolecules, 1997, 30, 6856.

16 L. Besnard, F. Marchal, J. F. Paredes, J. Daillant, N. Pantoustier, P. Perrin and P. Guenoun, Adv. Mater., 2013, 25, 2844.

17 W. D. Bancroft, J. Phys. Chem., 1913, 17, 501.

18 B. P. Binks, Colloids Surf., A, 1993, 71, 167.

19 B. P. Binks, Langmuir, 1993, 9, 25.

20 S. Khoukh, C. Tribet and P. Perrin, Colloids Surf., A, 2006, 288, 121.

21 W. C. Griffin, J. Soc. Cosmet. Chem., 1949, 1, 311.

22 J. T. Davies, Proc. 2nd Int. Cong. Surf. Activity, London, 1957.

23 J.-L. Salager, A. M. Forgiarini and J. Bullon, J. Surfactants Deterg., 2013, 16, 449.

24 W. D. Harkins, E. C. H. Davies and G. L. Clark, J. Am. Chem. Soc., 1917, 39, 541.

25 I. Langmuir, J. Am. Chem. Soc., 1917, 39, 1848.
26 R. Aveyard, B. P. Binks, T. A. Lawless and J. Mead, J. Chem. Soc., Faraday Trans. 1, 1985, 81, 2155.

27 C. Solans and I. Sole, Curr. Opin. Colloid Interface Sci., 2012, 17, 246.

28 H. T. Davis, Colloids Surf., A, 1994, 91, 9.

29 P. Winsor, Solvent Properties of Amphiphilic Compounds, Butterworth, London, 1954.

30 L. Belkoura, C. Stubenrauch and R. Strey, Langmuir, 2004, 20, 4391.

31 W. Jahn and R. Strey, J. Phys. Chem., 1988, 92, 2294.

32 N. Garti, Colloids Surf., A, 1997, 123, 233.

33 S. M. Gruner, J. Phys. Chem., 1989, 93, 7562.

34 A. Kabalnov, T. Tarara, R. Arlauskas and J. Weers, J. Colloid Interface Sci., 1996, 184, 227.

35 P. Perrin, Langmuir, 2000, 16, 881.

36 P. Perrin, N. Monfreux and F. Lafuma, Colloid Polym. Sci., 1999, 277, 89.

37 S. Khoukh, P. Perrin, F. B. de Berc and C. Tribet, ChemPhysChem, 2005, 6, 2009.

38 F. Marchal, A. Roudot, N. Pantoustier, P. Perrin, J. Daillant and P. Guenoun, J. Phys. Chem. B, 2007, 111, 13151.

39 L. Z. Hong, G. Q. Sun, J. G. Cai and T. Ngai, Langmuir, 2012, 28, 2332.

40 J. L. Salager, L. Marquez, A. A. Pena, M. Rondon, F. Silva and E. Tyrode, Ind. Eng. Chem. Res., 2000, 39, 2665.

41 J. A. Hanson, C. B. Chang, S. M. Graves, Z. B. Li, T. G. Mason and T. J. Deming, Nature, 2008, 455, 85.

42 P. Guenoun, S. Lipsky, J. W. Mays and M. Tirell, Langmuir, 1996, 12, 1425.

43 B. Vonnegut, Rev. Sci. Instrum., 1942, 13, 6.

$44 \mathrm{~J}$. P. Cotton, in Neutron, X-ray, and Light Scattering, ed. P. Lindner and Th. Zemb, Delta Series, North-Holland, Amsterdam, 1991.

45 L. T. Lee, D. Langevin and B. Farnoux, Phys. Rev. Lett., 1991, 67, 2678.

46 T. Cosgrove, J. S. Phipps and R. M. Richardson, Colloids Surf., 1992, 62, 199.

47 A. Zarbakhsh, J. Bowers and J. R. P. Webster, Meas. Sci. Technol., 1999, 10, 738.

48 A. Roudot, Ph. D. thesis, Université Pierre et Marie Curie, Paris, 2008.

49 G. Romet-Lemonne, J. Daillant, P. Guenoun, J. Yang, D. W. Holley and J. W. Mays, J. Phys. Chem., 2005, 122, 064703.

50 F. Muller, M. Delsanti, J. Yang, Y. J. Chen, J. W. Mays, B. Deme, M. Tirrell and P. Guenoun, Eur. Phys. J. E: Soft Matter Biol. Phys., 2000, 3, 45.

51 G. S. Manning, J. Phys. Chem., 1969, 51, 934.

52 F. Muller, P. Guenoun, M. Delsanti, B. Deme, L. Auvray, J. Yang and J. W. Mays, Eur. Phys. J. E: Soft Matter Biol. Phys., 2004, 15, 465.

53 F. Muller, G. Romet-Lemonne, M. Delsanti, J. W. Mays, J. Daillant and P. Guenoun, J. Phys.: Condens. Matter, 2005, 17, S3355.

54 P. Debye, J. Phys. Colloid Chem., 1947, 51, 18.

55 L. G. Parratt, Phys. Rev., 1954, 95, 359.

56 A. Nelson, J. Appl. Crystallogr., 2006, 39, 273. 
57 P. Auroy, Y. Mir and L. Auvray, Phys. Rev. Lett., 1992, 69, 93. 58 B. P. Binks, R. Murakami, S. P. Armes and S. Fujii, Angew. Chem., Int. Ed., 2005, 44, 4795.

59 T. Sottmann and R. Strey, J. Chem. Phys., 1997, 106, 8606.
60 M. Bourrel and R. S. Schechter, Microemulsions and Related Systems, New-York, 1988.

61 P. Guenoun, R. Gastaud, F. Perrot and D. Beysens, Phys. Rev. A: At., Mol., Opt. Phys., 1987, 36, 4876.

62 H. M. Tanaka, Prog. Theor. Phys., 1999, 101, 863. 